\title{
Construyendo la transición al socialismo: los proyectos de legislación laboral de la Federación Obrera de Chile (1920-1922)*
}

\author{
Building the transition to socialism: the law labor projects of \\ Federación Obrera de Chile (1920-1922)
}

Vicente Mellado Carrasco**

\begin{abstract}
Resumen: Se indaga en la elaboración y presentación de proyectos de legislación laboral por la Federación Obrera de Chile (FOCh) al Congreso Nacional durante el año 1921. Los proyectos presentados fueron: Cámaras del Trabajo, Tribunal de Conciliación y Contrato de Socialización Industrial. Estos buscaron entregar un alto poder de decisión a los trabajadores en la regulación de las relaciones laborales y el mercado de trabajo. Los proyectos combinaron orientaciones corporativistas y socialistas evolutivas, propias del pensamiento sindical y socialista del movimiento obrero chileno de la época. La adopción de ideas corporativistas constituyó una opción pragmática y defensiva de parte de la FOCh socialista, en vista de la coyuntura reaccionaria que debilitó al movimiento obrero. Sin embargo, la ambigüedad de semejantes ideas favoreció la visibilización de sectores al interior de la FOCh que se proclamaron defensores de un socialismo evolutivo que en varias ocasiones se hizo indistinguible del corporativismo. La FOCh abrigó la esperanza de que, bajo un clima político favorable a la reforma social, el Congreso aprobaría los proyectos de ley. Por el contrario, estos fueron rechazados por los partidos oligárquicos.
\end{abstract}

Palabras clave: Proyectos de ley laboral, Federación Obrera de Chile, socialismo, corporativismo, regulación laboral.

\begin{abstract}
The purpose of this study is to inquire about elaboration and presentation of labor legislation projects by Federación Obrera de Chile (FOCh) to the National Congress, during year 1921. Presented projects: Labor Chambers, Conciliation Court and Industrial Socialization Contract. These sought to deliver a high decision-making power to workers in the regulation of labor relations and labor market. The projects combined corporatist and evolutionary socialist orientations, typical of the union and socialist thought of the Chilean labor movement of the time. The adoption of corporatist ideas constituted a pragmatic and defensive option on the part of the socialist FOCh, in view of the reactionary situation that weakened the workers' movement. However, the ambiguity of such ideas favored the visibility of sectors within the FOCh that proclaimed themselves
\end{abstract}

\footnotetext{
* Agradezco los comentarios y sugerencias realizados por Juan Valenzuela, Sergio Grez Toso y los evaluadores externos. Todos contribuyeron en el mejoramiento del artículo que se publica a continuación. Los errores de interpretación, imprecisiones temporales y/ conceptuales son de absoluta responsabilidad del autor.

${ }^{* *}$ Historiador chileno, Licenciado en Historia por la Universidad de Chile y Magíster@ en Ciencias Sociales mención Sociología de la Modernización por la Universidad de Chile. Correo electrónico: vicente.mellado.c@gmail.com.
} 
defenders of an evolutionary socialism that on several occasions became indistinguishable from corporatism. The FOCh hoped that under a political climate favorable to social reform, Congress would approve the bills. On the contrary, these were rejected by the oligarchic parties.

Key words: Labor law projects, Federación Obrera de Chile, socialism, corporatism, labor regulation.

Recibido: 24 mayo 2018 Aceptado: 16 julio 2018

\section{Introducción}

Con las "marchas del hambre" del bienio de 1918-1919, se produjo la irrupción del movimiento de masas explotadas y pobres urbanos en Chile, acelerando el proceso de descomposición del régimen político liberal oligárquico nacido de la Guerra Civil de 1891. El triunfo electoral de Arturo Alessandri Palma en junio de 1920 como nuevo Presidente de la República de Chile - si bien asumió como tal en diciembre de ese año- abrió una nueva situación política favorable a la reforma social. Aprovechando el nuevo ciclo de lucha de clases abierto por la "cabalgata del monstruo"1, los trabajadores organizados que resistieron la crisis salitrera realizaron una serie de huelgas por demandas salariales y mejora de condiciones laborales desde 1919, alcanzando su apogeo en 1920². No resulta extraño que, durante ese bienio, el gobierno del "unionista" Juan Luis Sanfuentes haya reprimido violentamente a los gremios obreros y empleados, destacándose las masacres de Puerto Natales en enero de 1919 y la de Punta Arenas en julio de 1920. Durante el mismo bienio también fueron víctima de la violencia de Estado los estudiantes universitarios organizados en la Federación de Estudiantes de la Universidad de Chile (FECh) ${ }^{3}$.

No obstante la represión del gobierno de Sanfuentes, en diciembre de 1919 se reunieron en Concepción los delegados de la Federación Obrera de Chile (FOCh), realizando su III Congreso, el cual estableció como nuevos principios la abolición del sistema capitalista y su reemplazo por la FOCh. La incorporación del socialismo como horizonte político de la central sindical constituyó una muestra del fortalecimiento en su seno del Partido Obrero Socialista (POS) y del ala izquierda del Partido Democrático (PD). La FOCh votó un programa social que contempló una serie de demandas reconocidas por la Organización Internacional del Trabajo (OIT) - recientemente constituida en 1919- como derechos universales: jornada laboral de ocho horas, reglamentación de condiciones de trabajo, una nueva ley de accidentes del trabajo —derogando la de 1916 por ineficiente—, fijación de salario mínimo, entre otras medidas 4 .

\footnotetext{
1 Así denominó el historiador neoconservador Gonzalo Vial al movimiento obrero y popular urbano organizado en la Asamblea Obrera de la Alimentación Nacional durante los álgidos años de 1918 y 1919. Ver: "6. Cabalga el Monstruo" (pp. 600-604), en: Gonzalo Vial, Historia de Chile (1891-1973). Triunfo y decadencia de la Oligarquía (18921-1920), volumen II, Editorial Santillana del Pacífico, santiago de Chile, 1983.

2 Jorge Rojas Flores, El sindicalismo y el Estado en Chile (1924-1936), Colección Nuevo Siglo, 1986, pp. 74-75.

${ }^{3} \mathrm{Al}$ respecto ver, Sergio Grez Toso, Historia del Comunismo en Chile. La era de Recabarren (1912-1924), Santiago, Lom ediciones, 2011, pp. 106-109.

4 Juan Carlos Yáñez, “Chile y la Organización Internacional del Trabajo (1919-1925). Hacia una Legislación Social Universal”, Revista de Estudios Histórico-Jurídicos, Valparaíso, no 22, 2000, pp. 320-321.
} 
Entre 1919 y 1921 las coaliciones oligárquicas —Unión Nacional y Alianza Liberal— presentaron proyectos de legislación laboral al Congreso. Como se indagó en otro artículo5, la FOCh dio su apoyo al proyecto de Código del Trabajo de la Alianza Liberal. En las elecciones parlamentarias de marzo de 1921, los socialistas realizaron un pacto electoral con la Alianza Liberal llevando candidatos en común ${ }^{6}$. Esto le permitió a la FOCh llegar al Congreso con nueve diputados — dos socialistas, seis demócratas y un radical7 - , favoreciendo expectativas de que era posible aprobar leyes protectoras de trabajadores en el Congreso oligárquico. No obstante, la FOCh no se limitó a reproducir los planteamientos de los partidos oligárquicos y en simultáneo presentó al Congreso Nacional sus propios proyectos de ley laboral —Cámaras del Trabajo, Tribunales de Conciliación y Contrato de Socialización Industrial- solicitando su aprobación y —en algunas ocasiones - la integración de estos en la propuesta de Código del Trabajo del gobierno.

Como se verá más adelante, los proyectos de legislación laboral de la FOCh constituyen un objeto de escaso análisis de parte de la historiografía. Por ello se ha propuesto abordar el siguiente problema historiográfico: ¿Cuál fue el contenido y la finalidad estratégica de los proyectos de legislación social de la FOCh?

Este artículo sostiene que los proyectos laborales de la FOCh propusieron entregar un alto poder de decisión a los trabajadores en la regulación de las relaciones laborales al interior de las empresas y en el mercado de trabajo. Los proyectos se caracterizaron por sintetizar un socialismo evolutivo y concepciones corporativistas, ideas propias del movimiento obrero chileno de la época ${ }^{8}$. La adopción ambigua del corporativismo se explica por una opción pragmática y defensiva de parte de la FOCh socialista, en vista de la coyuntura desfavorable para impulsar tácticas ofensivas del movimiento obrero. Sin embargo, la adopción de estas ideas tuvo efectos contradictorios al propiciar el desarrollo de sectores al interior de la FOCh que se proclamaron defensores de un socialismo evolutivo que en momentos se hizo indistinguible del corporativismo. Por un lado, el proyecto de Contrato de Socialización Industrial tuvo por objetivo institucionalizar la participación de los trabajadores en la administración y gestión de las empresas junto a los patrones. Por otro lado, los proyectos de Cámara del Trabajo y Tribunal de Conciliación, si bien compartieron varios puntos con el anterior, se diferenciaron en proponer la constitución de un organismo colegiado y paritario de patrones y obreros cuya finalidad sería negociar condiciones comunes de trabajo. A pesar de los esfuerzos esgrimidos, la recepción de estos proyectos de ley de la central sindical por el Congreso Nacional fue de absoluto rechazo.

\footnotetext{
5 Vicente Mellado Carrasco, "El Código del Trabajo de la Alianza Liberal y la Federación Obrera de Chile (FOCH), 1920-1922", en Cuadernos de Historia, № 47, diciembre de 2017, pp. 59-84.

6 Sergio Grez, op. cit, 2011, pp. 121-131.

7 Los diputados federados fueron: Luis Emilio Recabarren (POS) por Antofagasta; Luis Víctor Cruz (POS) por Tarapacá; Ramón de la Vega (PD) por Quillota y Limache; Luis Correa Ramírez (PD) por Santiago; Juan Pradenas Muñoz (PD) por Lautaro; Manuel Navarrete (PD) por Coelemu y Talcahuano; Juan Vargas Márquez (PD) por Curanilahue; Óscar Chanks (PD) por Angol y Traiguén; y el ex presidente de la Federación de Estudiantes de la Universidad de Chile (FECh), Santiago Labarca (Partido Radical) por Santiago. Estos nueve diputados federados conformaron lo que se conoció como la "bancada obrera". Con posterioridad, Óscar Chanks fue expulsado de esta a fines de 1921 y reemplazado su lugar por Domingo Durán (Partido Radical), diputado por Temuco, Imperial y Llaima". Ver: Mellado, op. cit, 2017, p.71.

${ }^{8} \mathrm{Al}$ respecto ver: Jorge Rojas Flores, La dictadura de Ibáñez y los sindicatos (1927-1931), Santiago, DIBAM - Centro de Investigaciones Diego Barros Arana, 1993. Versión electrónica:

http://www.archivochile.com/Ideas_Autores/rojasfj/ rojasfj 0001.pdf; Sergio Grez Toso, "La Asamblea Constituyente de Asalariados e Intelectuales. Chile, 1925: entre el olvido y la mitificación”, en Revista Izquierdas $N^{o}$ 29, 1-48, septiembre de 2016. En particular páginas 19, 30 y 34-36.
} 
El periodo escogido - 1920 a 1922-es breve pero abundante en cuanto a la fluidez de la situación económica, social y política, en particular esta última. En otro artículo se abordó la ubicación política de la FOCh frente al proyecto de Código del Trabajo de la Alianza Liberal presentado al Congreso durante el mismo periodo9. Ahora es el turno de indagar en los proyectos laborales presentados por los organismos de trabajadores, en este caso, la FOCh.

Para cumplir los objetivos propuestos, se recurrió a fuentes periodísticas, folletería y archivos pertenecientes al Poder Legislativo. Entre las primeras se utilizó la prensa de la FOCh y El Mercurio, uno de los principales portavoces de la oligarquía chilena. El folleto utilizado corresponde al proyecto de "Constitución para una República Federal Socialista" de Luis Emilio Recabarren, de gran riqueza documental. Respecto a las últimas fuentes pesquisadas se revisaron las sesiones ordinarias y extraordinarias de la Cámara de Diputados y el Senado.

\section{Los proyectos laborales de la FOCh en la historiografía}

Los proyectos laborales de la FOCh fueron presentados al Congreso entre marzo y agosto de 1921. La asunción de los "diputados federados" en la cámara baja produjo expectativa en la FOCh de que lograría aprobar los proyectos con el apoyo de los parlamentarios aliancistas y del Presidente de la República ${ }^{10}$. En la historiografía marxista clásica chilena (1948-1973) es casi inexistente la referencia a los proyectos de legislación social de la FOCh. Algunas breves alusiones a las Cámaras del Trabajo se encuentran en la obra de Jorge Barría11.

Desde otra vertiente epistemológica, el sociólogo norteamericano James 0. Morris destacó la presentación del Contrato de Socialización Industrial por iniciativa de la Junta Ejecutiva Federal (JEF) de la central a la Comisión de Legislación Social de la Cámara de Diputados. Según Morris el Contrato de Socialización Industrial "distaba mucho de ser una proposición revolucionaria y, hasta cierto punto, afirmaba la fe y la confianza en el gobierno "burgués" "12. El autor no profundizó más en el problema planteado.

Será a partir de la década de 1990 con el desarrollo de la Nueva Historia Social chilena -en particular de su vertiente historiográfica laboral- que se reactivará la investigación del movimiento obrero de principios del siglo XX y su relación con la legislación social. Dentro de este periodo se encuentran las obras de Miguel Silva ${ }^{13}$ —investigación historiográfica con una explícita propuesta militante-, y María Angélica Illanes ${ }^{14}$. En cuanto al primero, en un par de párrafos evidenció la presentación al Congreso del proyecto de "Contrato de Socialización Industrial” a iniciativa de Luis Emilio Recabarren en 192115, limitándose a entregar una definición de los objetivos centrales de la propuesta. Respecto a la autora, dedicó una página para evidenciar la iniciativa de la clase obrera chilena en presentar su propio proyecto de

\footnotetext{
${ }^{9}$ Mellado, op. cit., 2017.

10 Al parecer, el proyecto de Contrato de Socialización Industrial fue presentado primero al Presidente de la República en el mes de febrero de 1921, antes de las elecciones parlamentarias. "Santiago. Buscando la socialización de las industrias", EL Socialista, Antofagasta, 24 de febrero de 1921.

11 Jorge Barría Serón, Los movimientos sociales de Chile. Desde 1910 hasta 1926 (Aspecto político y social), Memoria de Prueba para optar al Grado de Licenciado en Ciencias Jurídicas y Sociales, Universidad de Chile, Editorial Universitaria, 1960, pp. 135-136.

12 Morris, op. cit, p. 175.

13 Miguel Silva, Recabarren y el Socialismo, Mago editores, 2005 [1992].

14 María Angélica Illanes, "En el nombre del Pueblo, del Estado y de la Ciencia, (...)”. Historia social de la salud pública. Chile 1880-1973, Colectivo de Atención Primaria, Santiago, 1993.

15 Silva, op. cit, p. 236. Sin embargo, como se verá en este artículo, la iniciativa en la elaboración del proyecto le cupo al Secretario General de la FOCh en 1921, Enrique Díaz Vera, no a Recabarren.
} 
legislación laboral, "Las Cámaras del Trabajo", diferenciado de la propuesta alessandrista de Código del Trabajo, que buscaba hacer recaer en el Estado toda la iniciativa de resolver la cuestión social 16 .

En una de las obras más recientes acerca de la vida de Recabarren, Julio Pinto Vallejos abordó en breve la presentación del proyecto de Cámara del Trabajo o Tribunal de Conciliación del dirigente socialista. Según el autor, el proyecto fue congruente con "la promesa alessandrista" de resolver los problemas sociales que atravesaba Chile. En su presentación se propuso "la creación en cada provincia bajo supervisión estatal, de tribunales paritarios de obreros y empleadores, facultados para normar diversas cuestiones relacionadas con las condiciones de trabajo (...)"17.

En virtud de lo anterior, la obra de Juan Carlos Yáñez constituye una de las principales contribuciones al conocimiento de la legislación social en Chile de principios del siglo XX. En lo que respecta a la posición de los trabajadores, Yáñez afirmó que aquellos agrupados en la FOCh estuvieron a favor de una legislación laboral. Sin embargo, el autor no entregó mayores detalles de por qué se apoyó el Código del Trabajo propuesto por el gobierno y cómo se dio el proceso de evaluación del mismo al interior de las filas federadas ${ }^{18}$.

En cuanto a los proyectos de ley ${ }^{19}$ de la central sindical, Yáñez realizó una primera indagación ${ }^{20}$ analizando el proyecto de "Contrato de Socialización Industrial" de la FOCh presentado en febrero de 1921 al Congreso Nacional. En este artículo sostuvo que el "proyecto de los trabajadores coincidía en algunos aspectos con el del Partido Conservador y el del Partido Liberal" aludiendo a las demandas democráticas mínimas de reconocimiento universal, tales como: jornada laboral de ocho horas y 48 horas semanales; salario mínimo; y el reconocimiento de condiciones laborales mínimas. No obstante, el autor advirtió un par de elementos del proyecto de "Contrato..." ausentes en los proyectos oligárquicos: la resolución de problemas laborales de acuerdo a las particularidades de cada centro productivo y la creación de un Consejo de Administración que resolviera los conflictos que se suscitasen entre el capital y el trabajo. Según Yáñez, “[a]sí como estaba formulado el proyecto, hacía innecesaria la aprobación del Código Laboral, en cualquiera de sus formas, que pretendiese resolver integralmente el problema social en Chile. Además, le quitaba al Congreso la facultad de legislar sobre uno de los problemas más apremiantes del periodo parlamentario" 21.

Posteriormente, en su obra La Intervención Social en Chile, Yáñez dedicó algunas páginas de descripción de las tres propuestas legislativas de la $\mathrm{FOCh}^{22}$, sin entregar mayores detalles de su contraste con los proyectos conservador y liberal. Acorde al planteamiento de su obra, el autor destacó la coherencia de las propuestas legislativas obreras con el proceso global dirigido por el Estado chileno de integración de los trabajadores al espacio social y de institucionalización de las demandas laborales. Sin embargo, se puede reconocer que hubo una diferenciación de fondo entre ambos proyectos. El proyecto de Código del Trabajo de la Alianza

\footnotetext{
16 Illanes, op. cit, p. 190.

17 Julio Pinto Vallejos, Luis Emilio Recabarren. Una biografía histórica, Lom ediciones, 2013, pp. 206-207.

18 Esto se indagó en, Mellado, op. cit, 2017.

19 Los proyectos de ley elaborados por la FOCh y presentados al Congreso fueron los siguientes: La "Cámara del Trabajo" (julio de 1920); el "Contrato de Socialización Industrial” (enero 1921); y el "Tribunal de Conciliación” (junio de 1921). Ver: Juan Carlos Yáñez, La Intervención Social..., op. cit., pp. 159-163.

20 Juan Carlos Yáñez, "El proyecto laboral de la FOCh (1921). Los trabajadores frente a la Legislación Social”, Espacio de convergencia: primer y segundo encuentro de estudios humanísticos para investigadores jóvenes, Museo Nacional Benjamín Vicuña Mackenna, Santiago, agosto de 1999 y agosto de 2000, editor, Sergio Grez Tozo, 2001, pp. $249-261$. 21 Ibid, p. 259.

22 Juan Carlos Yáñez, La Intervención social en Chile..., op. cit., pp. 159-163.
} 
Liberal tuvo por objetivo estratégico "disciplinar" a la clase obrera reduciendo el antagonismo capital/trabajo al interior de las cuatro paredes de la empresa. Esto último es lo que se conoce como un sistema moderno de relaciones laborales: marco institucional fundamental de un Estado de Derecho que garantiza y protege el derecho de acceso individual a la propiedad privada de los medios de producción. Por el contrario, los proyectos de ley de la FOCh estuvieron puestos en función de entregar mayor poder social a los trabajadores al interior de las empresas, y en el caso del Contrato de Socialización Industrial, participación en la gestión y dirección de la industria en igualdad de derechos con los patrones. Lo que se demostrará a continuación es que los proyectos de legislación laboral de la FOCh constituyeron la concreción de una concepción específica - si bien no original de Chile- de cómo construir el socialismo y de la función social que le correspondió al sindicato o los gremios de trabajadores en la organización de la producción nacional.

\section{La FOCh y su “Programa Social” de 1919}

En el III Congreso Nacional de la FOCh realizado en diciembre de 1919 en Concepción, los delegados presentes votaron un "Programa Social" que contempló las siguientes demandas:

Por el mejoramiento de los salarios de manera que correspondan a las necesidades de la vida, en constante progreso hasta producir la transformación del régimen del salario, por un mejoramiento superior que concluya con la esclavitud del salario.

Por la disminución de las horas de trabajo como un medio de disminuir la desocupación y la fatiga para darse tiempo a la hijiene (sic) indispensable y a los deberes sociales.

Por la reglamentación de las condiciones de trabajo hasta hacer desaparecer todo vestigio de despotismo y esclavitud.

Por el abaratamiento de la vida, ya sea por medio de ajitaciones, influyendo en la lejislación de los impuestos, o creando o protejiendo instituciones cooperativas que tengan por objeto abaratar la vida.

Por el mejoramiento de las habitaciones y su abaratamiento por los medios que la fuerza creciente de esta Federación le sea permitida. ${ }^{23}$

La Convención de la FOCh publicó un manifiesto dando a conocer al gobierno "las inmediatas necesidades del pueblo". En este se afirmó que "la base de toda democracia descansa en el derecho, en la libertad y en la justicia" 24. En el Manifiesto, el apartado titulado "Libertad de organización, de huelga y pensamiento", interpeló al Estado para que reconociera el derecho de asociación de los trabajadores.

Los trabajadores de un confín a otro del país vienen pidiendo libertad y reconocimiento de sus organizaciones.

Esto ocurre porque el derecho que a este respecto nos da la Constitución es letra muerta en la práctica de los acontecimientos donde a diario se hostiliza al trabajador asociado, teniendo éste que acudir a la imposición por medio de la fuerza de su unión para hacerse respetar: a este respeto el Estado debe dar personalidad jurídica y legal a todos los organismos obreros, y así como se le garantiza al proletariado y a la clase capitalista, la libertad de trabajo, debe garantizar

${ }^{23}$ Adelante, Talcahuano, 6 de enero de 1920. "La Convención de la Federación Obrera de Chile en Concepción".

${ }_{24}$ Adelante, Talcahuano, 20 de enero de 1920, "De la Convención de la Federación Obrera. Manifiesto al Gobierno y al país en jeneral.-las inmediatas necesidades del pueblo". 
por el respeto y la consideración de las bases fundamentales del Estado, el derecho de asociación obrera. $^{25}$

En el Manifiesto se exigió al gobierno una ley de accidentes de trabajo, anulando la actual (de 1916) por no responder a los intereses obreros. También era necesario "una lei (sic) que fije el salario mínimun (sic) y la jornada de ocho horas es una necesidad popular que se hace sentir hondamente. La abolición de las pulperías y fichas en todos los establecimientos mineros e industriales del país, y la prohibición del expendio de las bebidas alcohólicas son de una imperiosa necesidad." El Manifiesto incluyó una política de erradicación del alcoholismo a nivel nacional e integró el pliego de peticiones del poderoso gremio de obreros ferroviarios de Chile. Esta impronta legalista de la denominada FOCh "revolucionaria y socialista" formó parte de su objetivo revolucionario:

(...) conquistar la libertad efectiva económica y moral, política y social de la clase trabajadora (obreros y empleados de ambos sexos), aboliendo el régimen capitalista con su inaceptable sistema de organización industrial y comercial, que reduce a la esclavitud a la mayoría de la población.

Abolido el sistema capitalista será reemplazado por la Federación Obrera, que se hará cargo de la administración de la producción y sus consecuencias. ${ }^{26}$

A partir de las publicaciones expuestas de la central sindical, es posible concluir que el puente que permitiría unificar las luchas por un régimen democrático más justo y el objetivo por el socialismo, era la lucha por el reconocimiento de derechos democráticos y sindicalesinexistentes en la sociedad chilena de principios de siglo XX. La inexistencia de estos derechos fundamentales habría producido una radicalización política de la noción de democracia identificándola con el socialismo.

\section{El Consejo Federal como organizador de la producción nacional27 y base de la construcción del socialismo}

En sus intervenciones en la Cámara de Diputados, Luis Emilio Recabarren dejó en evidencia que la tarea histórica de la FOCh era "dictar todas las leyes y con absoluta libertad de que deben gozar todos sus miembros, cuando la Cámara sea Cámara verdaderamente popular". Recabarren citó el diario La Vanguardia de Buenos Aires, perteneciente al Partido Socialista Argentino, para definir la función de los sindicatos. En algún número de 1916 el diario afirmó que:

Los sindicatos presentaran a los actuales industriales, las siguientes conclusiones: a partir de tal fecha, el sindicato intervendrá en la administración de la producción de la industria, y así mismo de la colocación de los productos para que sean tomados por los consumidores.

\section{5 Ídem.}

26 Adelante, Talcahuano, 27 de diciembre de 1919, "Federación Obrera. La sesión de ayer tarde. Informe de comisiones. Importantes debates. Triunfa la ensena roja. ¡Adelante! Es declarado órgano oficial de la Convención”.

${ }^{27}$ Se utiliza el concepto "producción nacional" en lugar de "economía nacional", que es al que hicieron referencia los proyectos laborales de la FOCh, correspondientes con las formulaciones políticas del periodo histórico en el que se plantearon. En ninguno de los proyectos laborales analizados se encontró una alusión explícita a la organización de la "economía nacional". 
La administración de cada taller, oficina, faena o fábrica o despacho de productos, será determinada por su respectivo personal, de acuerdo con la asamblea del sindicato.

El sindicato tomará las medidas que crea conveniente para simplificar y aumentar la economía en el modo de la producción, para economizar todos los esfuerzos que se gasten sin beneficio.

Según las condiciones de cada población el sindicato proveerá el aumento o disminución de los sitios en que sean colocados los productos para el consumo público.

En todos los locales establecidos por los sindicatos para almacenar los productos habrá empleados para facilitar la distribución, dependientes del sindicato, quienes entregarán al público los productos que demande sin cambio de moneda ni otro signo alguno.

El sindicato proveerá a la más perfecta administración de la distribución de los productos a los consumidores en orden a la comodidad creciente.

En virtud de esta disposición, los personales en los trabajos de todas las faenas productoras, distribuidoras o de otras condiciones, no gozarán salario alguno, serán productores libres, sujetos sólo a las resoluciones de sus respectivas asambleas, soberanas para reglamentar y administrar todo lo que se relacione con el perfeccionamiento del sistema productivo. ${ }^{28}$

Siguiendo la misma lógica, el dirigente sindical y socialista Sandalio Montenegro, de la Junta Provincial de Antofagasta, propuso que los consejos federales debían controlar los hospitales de los cantones salitreros para evitar el abuso de los médicos al servicio de las patronales salitreras ${ }^{29}$.

El gremio organizado de trabajadores constituyó la base de construcción de toda la estrategia socialista de la $\mathrm{FOCh}^{30}$. Los partidos que tenían presencia en la central sindical fueron concebidos como un "instrumento político" de los Consejos Federales que debían colocar sus reivindicaciones económicas en los espacios de participación que permitía el Estado: el Municipio y el Congreso Nacional. Por esto, en 1921 la FOCh obtuvo representantes en el Poder Legislativo del Estado, conocidos como diputados federados. Denominación que continuó incluso cuando desde 1922 se identificó a la FOCh con el Partido Comunista (PC). En síntesis, no existió una diferenciación estructural de identidad entre el gremio y los partidos políticos que se encontraban en su interior - en particular con los socialistas, después comunistas. Los problemas políticos prácticos que trajo esta identidad social y política para la posterior construcción del movimiento obrero y popular chileno no serán tratados en este artículo.

No obstante, en una situación histórica donde no existió una regulación de las organizaciones sindicales por parte del Estado, la relación de lo social y lo político fue muy fluida. El sindicato, gremio o consejo federal fue visto como un organismo capacitado no sólo para exigir reivindicaciones económicas, sino para ejercer funciones sociales, de organización del sistema productivo y la sociedad, otorgándole un carácter más político. Por esto no resulta extraño que este periodo histórico de organización laboral se conociera con el nombre de "sindicalismo libre": aquel movimiento obrero que no estuvo regulado por la acción del Estado y que combinó en su seno funciones sindicales y de acción política. Esto produjo que para los dirigentes fochistas la diferencia entre un soviet —organismo de doble poder en una situación

28 "Debate parlamentario. La palabra revolucionaria del apóstol del socialismo", El Socialista, Antofagasta, 6 de agosto de 1921.

29 "Puntos de vista. Trabajo por realizar", El Socialista, Antofagasta, 2 de marzo de 1921.

30 Acerca de la historia de la FOCh, su composición interna, estructura organizativa y orientación política ver: Durán Mateluna, Francisca, La Federación Obrera de Chile, 1909-1921: De la Organización Mutual al Frente Común. Pontifica Universidad Católica de Chile. Facultad de Historia, Geografía y Ciencias Políticas. Instituto de Historia. Profesor Guía: Julio Pinto Vallejos. Santiago, 2002; Mellado Carrasco, Vicente, Del Consejo Federal al Sindicato Legal: la Federación Obrera de Chile (FOCh) y el inicio de la transición a un sistema moderno de relaciones laborales (1919-1927), Universidad de Chile, Facultad de Filosofía y Humanidades, Departamento de Ciencias Históricas, Profesor guía: Sergio Grez Toso, 2013, pp. 24-58. 
revolucionaria- y un sindicato se hicieran más difusas, al otorgarle a éste algunas funciones más propias y características del primero, como fue la construcción de un nuevo orden social y productivo.

De este modo, la FOCh se planteó el problema del poder político, y proyectó su lógica de organización social y política como el germen de un futuro "Estado federal de trabajadores". La máxima expresión de esto lo constituyó el "Proyecto de Constitución para la República Federal Socialista de Chile"31, escrito por Recabarren como folleto en 1921, el año de presentación de los proyectos de ley laboral en el Congreso. El folleto contiene profundos aspectos del -como diría Jaime Massardo- "imaginario político" de Recabarren ${ }^{32}$.

\section{El Proyecto de Constitución para la República Socialista de Chile: el municipio y la socialización de la producción}

El Proyecto de Constitución para la República Federal Socialista de Chile, se publicó como folleto en mayo de 1921 por la imprenta El Socialista de Antofagasta. Fue escrito por Luis Emilio Recabarren durante su estadía en prisión en Tocopilla en $1920^{33}$. A diferencia de los proyectos laborales, no fue presentado al Congreso.

Según el folleto del "Proyecto de Constitución...", todas las empresas del país con más de diez trabajadores mayores de 18 años serían nacionalizadas. A continuación se procedería a la abolición de "toda propiedad particular o privada" 34 . La organización de los lugares de trabajo del país sería administrada por asambleas industriales que elegirían delegados a los municipios ${ }^{35}$. Estos constituyen el organismo fundamental de administración pública de los trabajadores en la nueva república federal socialista o "estado obrero" 36 . Los municipios, donde el pueblo sería la mayoría, se constituirían en los espacios donde los delegados de empresa (asambleas industriales) podrían elaborar sus reglamentos. De este modo se lograría "socializar el estado burgués" 37. En otras palabras, el nuevo Estado descansaría en la representación política (municipal) de los centros de producción, no en el tradicional parlamento republicano que separa al ciudadano de la producción.

La máxima instancia de resolución legislativa y ejecutiva de la nación sería la asamblea nacional, compuesta por delegados de cada municipalidad del país. Los consejos federales y demás organizaciones laborales, desde sus lugares de trabajo, dirigirán los municipios. En caso de que los industriales no aceptaran la decisión del pueblo de nacionalizar las empresas, el camino para imponerla sería la huelga general.

\footnotetext{
${ }^{31}$ Luis Emilio Recabarren, ¿Qué es lo que queremos federados y socialistas? Proyecto de Constitución para la República Federal Socialista de Chile, Antofagasta, Imprenta El Socialista, 1921.

32 Jaime Massardo, La formación del imaginario político de Luis Emilio Recabarren, Lom ediciones, 2007.

33 "El folleto más interesante para los federados", El Socialista, Antofagasta, 28 de abril de 1921. Respecto a la prisión de Recabarren en Tocopilla, ver: Pinto, op. cit, 2014, pp. 185-188.

${ }^{34}$ Recabarren, op. cit, p. 2. Resulta interesante señalar que la alusión a la abolición de la propiedad privada de las industrias y empresas comerciales no se contempló en ninguno de los proyectos de legislación laboral de la FOCh presentadas al Congreso en 1921.

35 Recabarren, op. cit, 1921, p. 7. Acerca de Recabarren y su concepción del municipio ver: Gabriel Salazar Vergara, “Luis Emilio Recabarren y el Municipio en Chile (1900-1925)”, Revista de Sociología No9, 1994, pp. 61-82; Gabriel Salazar Vergara, Del poder constituyente de asalariados e intelectuales. (Chile, siglos XX y XXI), Lom ediciones, 2009, pp. 121-149; Massardo, op. cit, 2007, pp. 233-241.

${ }^{36}$ Respecto al municipio y su utilización política al servicio de los sectores populares ver, Illanes, María Angélica, Chile Descentrado. Formación socio-cultural republicana y transición capitalista (1810-1910), Lom Ediciones, 2003, “El fruto prohibido de la guerra civil: el pueblo como poder. Valparaíso 1891-1897”, pp. 463-494.

37 Recabarren, op. cit, 1921, p. 8.
} 
La importancia del municipio como eje articulador de la administración de la propiedad nacionalizada queda de manifiesto en el siguiente punto del folleto: "En cada comuna la municipalidad es el único poder legislativo y ejecutivo encargado de todos los asuntos de interés general dentro de la comuna" 38 . Según Recabarren, la "propiedad nacional" es lo que los socialistas denominan "socializar la propiedad porque cada comuna y cada nación es una sociedad de seres humanos"39. De este modo se lograría - utilizando la misma frase del socialista utópico Claude Henri conde de Saint Simon ${ }^{40}$ - "la magnífica administración de las cosas". El proyecto de Constitución logrará ser Ley de la República "cuando la Federación Obrera de Chile tenga suficiente capacidad" 41 ocupando los municipios y utilizando la huelga general de ser necesario.

Resulta importante destacar que a diferencia de los proyectos laborales de la FOCh presentados al Congreso en 1921, el "Proyecto de Constitución..." sostuvo en sus primeros párrafos la abolición de la propiedad privada de las industrias y empresas comerciales. Esta afirmación es coincidente tanto con la declaración de principios de la FOCh en 1919 — que se propuso la abolición del sistema capitalista y su reemplazo por ésta en la administración de la producción - como con el programa político del POS de $1915^{42}$. Por el contrario, en los proyectos de legislación laboral presentados por la FOCh dicho fin programático-estratégico estuvo ausente. Esto permite advertir acerca de la dirección y finalidad que tuvieron los proyectos laborales.

Los proyectos de legislación social; la existencia de diputados federados (hasta 1922 fueron cinco demócratas, dos socialistas y dos radicales) en el Congreso ${ }^{43}$; la identificación posterior entre la FOCh y el PC; los conceptos de "administración de la producción" y "socialización industrial", entre otros indicadores, constituyen la evidencia histórica de la originalidad del pensamiento socialista de un sector del movimiento obrero chileno. A diferencia del bolchevismo soviético que integró como aspecto medular de su estrategia el problema de la insurrección proletaria para la toma del poder político, el socialismo chileno omitió ese aspecto, enfatizando en la conquista de posiciones municipales y parlamentarias en el Estado capitalista como el medio para avanzar hacia el socialismo. Para Recabarren los sindicatos y la educación de los trabajadores chilenos constituyeron el aspecto fundamental para preparar a la clase obrera en la construcción del socialismo. Era la manifestación concreta del movimiento real de los trabajadores urbanos de Chile.

\footnotetext{
38 Ibíd, p. 4.

39 Ídem.

40 Claude-Henri de Rouvroy, Conde de Saint-Simon (1759-1825) fue un socialista utópico francés que sostuvo que la industria productiva debía ser controlada por la sociedad de los "industriales" (empresarios productores, banqueros, científicos, innovadores de la tecnología, y obreros). Fue la primera doctrina socialista que se opuso al capitalismo liberal y a las clases dominantes "parasitarias y ociosas", es decir, los rentistas y nobles que vivían de la tierra. Para paliar los antagonismos de clase, en una primera fase, la sociedad debía organizarse en base a la planificación del Estado, para luego, abolidos los antagonismos de clase, el Estado se aboliría, y se pasaría a la "administración de las cosas". Al respecto ver: Eric Hobsbawm, "Marx, Engels y el socialismo premarxiano". En: Historia del Marxismo. El Marxismo en Tiempos de Marx (I), Editorial Bruguera, 1979, pp. 58-60; “Sansimonismo”, en: Lezsek Kolakowsky Las principales corrientes del marxismo. I. Los Fundadores. Alianza Editorial, 1976, pp. 191-196.

41 Ibíd, pp. 8-9.

${ }^{42} \mathrm{Al}$ respecto ver: Fernando Ortiz Letelier, Historia del movimiento obrero en Chile. 1891-1919, Lom ediciones, 2005 [1956], pp. 244-245.

43 Mellado, op. cit, 2017, p. 71.
} 


\section{Los proyectos laborales de la FOCh: ¿respuesta defensiva a una coyuntura reaccionaria?}

El marco temporal de presentación de los proyectos laborales de la FOCh correspondieron al año 1921, el cual se enmarcó en una de las fases históricas de declive en el tamaño y efectividad del movimiento obrero chileno definida por DeShazo (1921-1923) ${ }^{44}$ y coincidió con el inicio de un periodo de alza de los bienes de consumo de primera necesidad (1922-1925) ${ }^{45}$. La coyuntura política del año 1921 se caracterizó por ser reaccionaria, debido a la fuerte ofensiva patronal contra los sindicatos y los cierres de empresas que se produjeron.

Con la llegada al Congreso de los dos diputados socialistas y federados, la FOCh elaboró tres proyectos de ley que envió en abril de 1921 a la Comisión de Legislación Social de la Cámara de Diputados, como primera fase de discusión antes de su aprobación en el Congreso. Cuando al mes siguiente la Alianza Liberal envió el proyecto de Código del Trabajo a la Cámara Baja, la FOCh intentó que sus proyectos en trámite deliberativo fuesen aprobados en conjunto con este. Los proyectos federados fueron: la "Cámara del Trabajo", el "Tribunal de Conciliación", y el "Contrato de Socialización Industrial".

El proyecto de ley de Cámara del Trabajo fue aprobado en julio de 1920 por la Convención de la FOCh en Santiago, y publicado en la prensa federada del Norte salitrero en enero de 1921, con la aprobación de la Convención de Consejos Federales de la Pampa ${ }^{46}$. En su publicación, firmaron abajo, el gásfiter Enrique Salas, Eduardo Henríquez y el empleado comercial Eduardo Bunster. En abril de 1921, Salas fue electo regidor municipal de Iquique, como candidato del POS ${ }^{47}$. Bunster se candidateó como regidor federado por Santiago en las elecciones de abril en 1921, sin resultar electo ${ }^{48}$. De Henríquez no se obtuvo información.

El segundo proyecto, titulado Tribunal de Conciliación y conocido también como Cámara del Trabajo, fue redactado por el diputado federado y socialista Luis Emilio Recabarren en Antofagasta, durante julio de 192149. Por último, el proyecto de Contrato de Socialización Industrial fue redactado por la JEF de Santiago, a inicios de 1921 y presentado al gobierno de Alessandri en febrero de 192150. A la sazón, la JEF estuvo compuesta por: Recabarren (POS), Manuel Hidalgo (POS), Antonio Rodríguez (POS), el ya mencionado Eduardo Bunster

\footnotetext{
44 DeShazo, op. cit, 2007[1983], pp. 257-298.

45 Mario Matus González, "Salarios y sueldos reales de los operarios y empleados metalúrgicos industriales chilenos, 1888-1928”, en, Mario Matus G. (ed.), Hombres del Metal. Trabajadores ferroviarios y metalúrgicos chilenos en el Ciclo Salitrero, 1880-1930, Ediciones Facultad de Filosofía y Humanidades de la Universidad de Chile, 2009, p. 53.

46 “Un proyecto importante de la Federación Obrera de Chile. Cámara del Trabajo", El Despertar de Los Trabajadores, Iquique, 7 de enero de 1921.

47 Grez, op. cit, 2011, p.125.

48 "Sección Sociabilidad Obrera. Sobre la Ley de Descanso Dominical”, El Mercurio, Santiago, 29 de marzo de 1921, p. 16; "Sección Sociabilidad Obrera. Federación Obrera de Chile", El Mercurio, Santiago, 10 de abril de 1921; "Sección Sociabilidad Obrera. Proclamación de un candidato obrero", El Mercurio, Santiago, 4 de abril de 1921, p. 14.

49 "Cámara del Trabajo o Tribunales de Conciliación", por Luis Emilio Recabarren, La Federación Obrera, Santiago, 21 de agosto de 1921.

50 "Santiago. Buscando la socialización de las industrias", EL Socialista, Antofagasta, 24 de febrero de 1921; "Proyecto de Contrato de Socialización Industrial. Aprobado por la Junta Ejecutiva Federal”, El Despertar de Los Trabajadores, Iquique, 1ำ de marzo de 1921; “Carta Abierta. Junta Ejecutiva Federal. Al diputado Luis Correa Ramírez. Proyecto de Socialización Industrial”, por Enrique Díaz Vera, La Federación Obrera, Santiago, 1 de octubre de 1921.
} 
(sindicalista "puro"), y el Secretario General, Enrique Díaz Vera (POS), entre otros delegados de provincias ${ }^{51}$. Este último fue uno de los máximos impulsores del proyecto.

Como se verá más adelante, los tres proyectos laborales tuvieron como finalidad entregar un alto grado de poder de decisión a los trabajadores en la regulación de las relaciones laborales al interior de la empresa y el mercado laboral. Todos contemplaron como eje central la creación de organismos colegiados con participación paritaria de trabajadores y empresarios con el objetivo de resolver pacíficamente los conflictos del capital y el trabajo.

No resulta forzado afirmar que en vista de la coyuntura económica y política chilena del bienio de 1921-1922, los dirigentes fochistas junto a sus diputados federados prefirieran optar por proyectos de ley que regularan el mercado de trabajo y las relaciones laborales al interior de las empresas. Proponer la abolición de la propiedad privada de los medios de producción habría constituido un fin programático ofensivo que planteaba de modo directo la construcción de un orden socialista. Por el contrario, los proyectos de ley constituyeron una táctica de carácter más defensivo que buscaron crear condiciones favorables para la recuperación del poder social y económico perdido por los trabajadores durante este periodo.

Si bien la táctica elegida por la FOCh estuvo acorde con los principios socialistas y anti capitalistas votados en 1919, el mismo carácter de las corporaciones obrero-patronales propuestas también produjo un deslizamiento hacia postulados más corporativistas que socialistas. Esto se observa en la presencia de postulados que rechazan la discusión política al interior de los órganos propuestos, o - como se verá en el Contrato de Socialización Industrial - la búsqueda activa de colaboración con la parte patronal en la coadministración de la empresa.

\section{Las Cámaras del Trabajo}

Las Cámaras del Trabajo constituyen una demanda histórica del movimiento obrero organizado, tanto chileno como internacional, del periodo previo a la Primera Guerra Mundial (1914-1918). La FOCh no fue la única entidad gremial del país que preconizó la necesidad de constituir organismos colegiados entre empresarios y trabajadores para resolver los problemas económico-sociales de un territorio determinado.

En 1917, en la lejana región austral de Chile la Federación Obrera de Magallanes (FOM) logró constituir Cámaras del Trabajo cuyo objetivo era establecer relaciones armónicas entre el capital y el trabajo. La FOCh reivindicó la organización obrera magallánica como modelo a seguir por los trabajadores de todo el país. A pesar del incendio perpetrado por "bandas patrióticas" el fatídico 27 de julio de 1920, que dejó varios obreros muertos, la Cámara del Trabajo sobrevivió como el modelo regulador de las relaciones entre el capital y el trabajo en la región magallánica52.

No obstante, los referentes a seguir no se limitaron al territorio nacional. El dirigente fochista de Antofagasta, Sandalio Montenegro, reivindicó las Cámaras del Trabajo constituidas

\footnotetext{
51 "Junta Ejecutiva Federal”, La Federación Obrera, Santiago, 25 de agosto de 1921. Enrique Díaz Vera fue elegido Secretario General de la JEF de la FOCh en enero de 1920 y ejerció el cargo hasta diciembre de 1921. Luego ocupó su lugar Carlos Alberto Martínez hasta 1923. Ver: Barría, op. cit, p. 130, p. 143, p. 146 y p. 153.

52 "Vida Obrera. La Federación Obrera de Magallanes. (de "La Nación" de Santiago), El Socialista, Antofagasta, 13 de septiembre de 1921. En el artículo publicado en la prensa de la FOCh del Norte Grande la fecha que se atribuye a la formación de la Cámara del Trabajo de Magallanes es de 1919. Sin embargo, el historiador Sergio Grez Toso afirma que su constitución data de 1917 y que después de la represión del 27 de julio de 1920 fue suprimida. Al respecto ver, Sergio Grez Toso, “AAutonomía o escudo protector? El movimiento obrero y popular y los mecanismos de conciliación y arbitraje (Chile, 1890-1924)”, en Historia, vol. 35, Santiago, 2002, pp. 91-150. Ver acápite "La original experiencia de la Cámara del Trabajo en Magallanes".
} 
en Uruguay como "la más sólida de las instituciones de lucha abierta, contra el imperialismo capitalista”. El dirigente nortino planteó que en Mejillones el Consejo Federal había intentado constituir una Cámara del Trabajo recibiendo la negativa por parte de las autoridades y los industriales. Lo mismo ocurrió en los cantones salitreros. Montenegro dejó con gran clarividencia el sentido estratégico que comportaron las Cámaras del Trabajo para la FOCh:

(...) el camino progresivo de la humanidad, hacia los ideales de perfeccionamiento, es rectilíneo, invariable. (...) Para caminar por la senda de la evolución intelectual, mientras los hombres se preparan para vivir mejor, existen los caminos de la violencia y de la armonía. Donde la burguesía no acepta la armonía, donde se niega a reconocer los derechos que tienen los productores a la parte racional de su trabajo, se produce la violencia, la revolución con las armas en la mano y la guerra civil como sucede en España y en Ejipto. En cambio, hay naciones como Suisa, Checo Eslovaquia y otros donde la revolución se hace pacíficamente, las nuevas orientaciones se deslíen por medio de concesiones progresivas que la clase capitalista da a los trabajadores.

La Cámara del Trabajo es el medio tranquilo de hacer la evolución. Ella impide que la tiranía capitalista, en su desborde, en sus ansias jamás satisfechas de acapa-Establece (sic) la armonía necesaria entre los factores: Capital trabajo ${ }^{53}$.

El artículo de Montenegro es de una gran riqueza literaria en tanto que entrega las ideas fuerza de la estrategia sindical-socialista de la FOCh. Según Jaime Massardo, la idea de un socialismo evolutivo de raigambre "guesdiste" 54 y franco-belga fue sustancial al "imaginario político" de Recabarren. No obstante, como se verá más adelante, es posible afirmar que semejante imaginario puede atribuirse — si bien de modo desigual - al conjunto de los dirigentes de la FOCh. En estos es posible identificar dos ideas estratégicas de cómo construir el socialismo. Primero, el paso de la democracia al socialismo sería un proceso lineal libre de contradicciones. Segundo, la base material de construcción de la sociedad socialista serían los consejos federales o sindicatos. Estas dos ideas fuerza estuvieron cruzadas por una concepción radical de la participación democrática de los trabajadores en la elaboración de las leyes que rigieran los destinos de la nación. No obstante, es posible detectar en la propuesta de Cámara del Trabajo una tercera idea fuerza: la organización corporativa de la sociedad.

Por corporativismo ${ }^{55}$ se define la organización de la sociedad según la función de las personas, las que se organizan en grupos o gremios afines por actividad económica. Para el corporativismo, la organización gremial o sindical constituye un elemento poderoso de pacificación y unión de las distintas clases sociales. El gremio es creador de una estructura que facilitará la armonía entre los integrantes de la sociedad (capitalistas y trabajadores) y así alcanzar el objetivo común de progreso económico y social. El sindicato realiza el movimiento vital de coordinar las funciones productivas con el fin de lograr el bien de la nación, es decir, la armonía entre el capital y el trabajo. En este sentido, el fomento de una organización social basado en corporaciones, como son las Cámaras del Trabajo, "puede" implicar la exclusión de los partidos políticos y el rechazo a la actividad política, partidista y electoral ${ }^{56}$. En conclusión,

\footnotetext{
53 “Organización de la Cámara del Trabajo”, El Socialista, Antofagasta, 28 de febrero de 1921.

54 Guesdisme: alude a Jules Guesde, dirigente socialista francés fundador del Parti Ouvrier en 1893. Su idea de socialismo se representó como una ideología del progreso. Al respecto ver: Massardo, op. cit, pp. 222-227.

55 También se le conoce como "funcionalismo". Hemos extraído la definición de la obra de Rojas, op. cit, 1993, pp. 47-59. Sobre el pensamiento corporativista ver: León Duguit, La transformación del Derecho Público, Madrid, 1913. 56 Se debe diferenciar el "corporativismo" como ideología o estrategia política definida de lo que Antonio Gramsci denominó "momento económico-corporativo". Este se define como la actividad de los trabajadores —o de una clase social determinada - limitada a la lucha gremial. En el caso de la clase obrera, el efecto político que tiene limitar su
} 
el corporativismo tiene por fin neutralizar los conflictos entre las clases fundamentales de la sociedad capitalista, promoviendo su colaboración.

Sin embargo, como afirmó Jorge Rojas para el periodo de 1924 a 1931, el estudio de las ideas corporativas tiene por dificultad definir el concepto, "empleado múltiples veces con tal vaguedad que bien podía llegar a implicar el poder exclusivo para los trabajadores tanto como un régimen corporativo de conciliación de clases. De ahí la confusa vinculación que llegó a establecerse entre la doctrina corporativista y la sindicalista o gremialista (...)" 57 . Para dar cuenta de este fenómeno social, el autor realizó una pormenorizada investigación de la presencia de ideas corporativistas en los gremios de orientación anarcosindicalista durante el periodo mencionado ${ }^{58}$. Para un proceso histórico posterior al que estudia este artículo, Sergio Grez evidenció la presencia de ideales corporativistas en la Asamblea Constituyente de Asalariados e Intelectuales o "constituyente chica" de marzo de 192559. En esta instancia el autor evidenció como el PC promovió una representación corporativa de la Asamblea de Asalariados para favorecer su representación "gremial" en la FOCh. Similar análisis realizó Jorge Rojas en su obra ya citada, al afirmar que los comunistas apoyaron la creación de una "Cámara Funcional" en la "constituyente chica" con la finalidad asegurar la representación gremial de la clase obrera, lo que favorecería a esta fuerza política que tenía gran presencia al interior de una de las organizaciones gremiales más importantes del país: la FOCh ${ }^{60}$. De este modo, "aunque el funcionalismo se caracterizaba por la conciliación entre las clases, los comunistas lo entendían como una forma de mejorar las condiciones para alcanzar la dictadura del proletariado"61

En conclusión, se puede atestiguar la presencia de similares concepciones corporativistas en los tres proyectos de ley de la FOCh en función de crear espacios que posibilitaran a los trabajadores adquirir mayor poder social al interior de las industrias. Sin embargo, no estuvieron libres de críticas por la militancia sindical más cercana al socialismo marxista. La adopción de ideas corporativistas por parte de un sector de la central sindical se puede explicar por la orientación defensiva que tuvo esta durante el bienio de 1921-1922 y por las expectativas que tuvo durante el primer semestre de 1921 en el gobierno de Alessandri. No obstante, el socialismo evolutivo, al sostener que el avance desde la democracia hacia el socialismo constituye un proceso lineal libre de contradicciones, facilita el deslizamiento - ya sea voluntario o involuntario- a ideas que privilegian la colaboración y no la confrontación entre las clases sociales. Esta afirmación permite comprender las contradicciones inherentes a la FOCh en cuanto a las estrategias adoptadas para alcanzar el socialismo y en sus relaciones con los poderes públicos del Estado y las patronales en las distintas coyunturas políticas que se presentaron durante aquellos años de la "cuestión social".

En julio de 1920 la FOCh realizó una convención extraordinaria en Santiago para determinar su orientación política ante la nueva situación abierta después de las elecciones

actividad a la lucha gremial es bloquear la posibilidad de que los intereses corporativos de esta se conviertan en intereses que abarquen otros grupos subalternos, es decir, que la clase obrera pueda ser un sujeto hegemónico. Al respecto ver: Antonio Gramsci, "Análisis de situaciones y relaciones de fuerzas", Cuaderno 13 §17 (1932-1934), Cuadernos de la Cárcel, Tomo 5, Ediciones Era, 1975, pp. 32-40.

57 Rojas, op. cit, 1993, p. 48.

58 Ibíd.

${ }^{59} \mathrm{Al}$ respecto ver: Grez, op. cit, 2016, p. 19.

60 Rojas, op. cit, 1993, pp. 51-52.

${ }^{61}$ Ibíd., p. 52. 
presidenciales de junio de ese año. El presidente de la conferencia, el obrero salitrero Enrique Salas, manifestó que el objetivo principal de la convención era luchar por

(...) una Cámara del Trabajo que controle el cumplimiento de la lejislación vijente sobre trabajo que lleve estadística y que sirva de intermediaria entre el obrero y el Gobierno. pensamos tambien, pedir se apruebe la ley del salario mínimo y varias otras leyes y reformas de leyes que están haciendo mucha falta para establecer el trabajo sobre una base de orden y una garantía de equidad 62 .

En su artículo 1ํㅡㄹ la Cámara del Trabajo estableció que “(...) tiene por objeto servir de órgano regular en las relaciones entre capital y el trabajo". En su artículo $2^{\circ}$, se afirmó que "Se compone de dos entidades — patrones y trabajadores - que obran separadamente en defensa de sus respectivos intereses y conjuntamente en el anhelo común de salvar todas las dificultades que se oponga a la marcha normal del trabajo de la industria y el comercio". En su artículo 8ㅜㅜ "Corresponde a los delegados de los patrones y los obreros el nombramiento de un tribunal de conciliación y arbitraje, compuesto de 3 miembros designados por cada parte, y el 3ㅜ, en acuerdo de ambas" 63 . A diferencia del proyecto de Recabarren de 1921, el de la Cámara del Trabajo de 1920 prescribió en el inciso $10^{\circ}$ de sus "Disposiciones Fundamentales", que, "Se prohíbe en el seno de la Cámara las discusiones sobre política y religión"64. Esta constituye una disposición que puede interpretarse como corporativista, al excluir la discusión política en su seno. Sin embargo, también se podría preguntar si no constituye un elemento de continuidad con la tradición mutualista que todavía impregnaba al asociacionismo obrero y que establecía las mismas prohibiciones para los gremios de trabajadores desde la segunda mitad del siglo XIX 65 .

En el "Reglamento Interno" de la Cámara del Trabajo se contempló la regulación de las condiciones de trabajo, asumiendo los puntos aprobados en el Programa Social del III Congreso de la FOCh de 1919: establecimiento de la jornada laboral de cuarenta y ocho horas semanales distribuidas "durante la semana en la forma que mejor cuadre con la naturaleza del trabajo de cada gremio"; prohibición del trabajo a menores de 14 años; salario mínimo; realización de contratos colectivos. Por último, el funcionamiento de las Cámaras del Trabajo sería permanente.

El primer intento de concretizar esta propuesta de la FOCh — votada en julio de 1920fue cuando se produjo una de las tantas huelgas generales en la industria carbonífera. Como sostuvo Hernán Venegas, entre 1920 y 1927, la zona del carbón (cordón Coronel-LotaCuranilahue-Lebu), se convirtió en uno de los epicentros de la lucha de clases en Chile ${ }^{66}$. Las crisis económicas en la industria carbonífera eran frecuentes desde 1910. Su explicación reside en la contracción de la demanda internacional del mineral y la consiguiente baja del precio del mismo, que después de la Primera Guerra Mundial adquirió ribetes alarmantes. Ante semejante situación, se produjo la famosa "huelga grande" del carbón entre fines de febrero y principios

62 "El objetivo social de la Federación Obrera de Chile”, El Socialista, Antofagasta, 29 de julio de 1920.

63 “Un proyecto importante de la Federación Obrera de Chile. Cámara del Trabajo", El Despertar de Los Trabajadores, Iquique, 7 de enero de 1921.

64 Ídem.

65 Al respecto ver: Sergio, Grez Toso, De la "regeneración del pueblo" a la huelga general. Génesis y evolución histórica del movimiento popular en Chile (1810-1890), Santiago, RIL Editores, 2007, 2ª edición [1997].

66 Hernán Venegas Valdebenito, “Crisis económica y conflictos sociales y políticos en la zona carbonífera, 19181931”, Revista Contribuciones Científicas y Tecnológicas, № 116, Santiago, noviembre de 1997, 124-152. 
de mayo de 1920. En ella se vieron involucrados alrededor de 10 mil trabajadores de todo el cordón industrial carbonífero. Entre noviembre y diciembre de 1920, se produjo otra huelga de obreros del carbón que conquistó la solidaridad de los trabajadores de toda la región, desde Tomé hasta Curanilahue. En esta ocasión el número de obreros involucrados llegó a 40 mil67.

Como resultado de las sucesivas huelgas carboníferas, a inicios de 1921 el gobierno tomó la iniciativa de crear un Tribunal de Conciliación y Arbitraje permanente en la zona68. Para llevar a cabo esta tarea se constituyó una comisión parlamentaria especial que estudiara la formación del tribunal ${ }^{69}$. De este modo, el Ministerio de Industrias y Obras Públicas dirigido por el demócrata Zenón Torrealba organizó una reunión donde asistió la comisión parlamentaria, representantes empresariales, integrantes de la OT y de Ferrocarriles del Estado, y delegados de la FOCh. El ministro Torrealba planteó a los obreros que aceptaran la formación del tribunal y la forma en que el organismo desarrollaría su acción. Fue en ese momento de negociación que los delegados de los consejos federales del carbón propusieron a la comisión parlamentaria la constitución de una Cámara del Trabajo según las disposiciones fundamentales votadas en julio de 1920 en la Convención de Santiago. La respuesta de la comisión parlamentaria y de los representantes patronales fue de absoluto rechazo. Por su parte, la FOCh carbonífera acogió "en principio la constitución del Tribunal Arbitral”, pero sin que ello significara su aprobación definitiva, ya que primero debían consultar "a sus respectivos compañeros de trabajo"70. Días más tarde, los delegados de Coronel y Lota declararon que "sus compañeros aceptarían únicamente el organismo que denominan Cámara del Trabajo, corporación que estiman les daría suficientes garantías"71. La comisión parlamentaria respondió que estudiaría la petición obrera e informaría al gobierno antes del 30 de abril.

En simultáneo, el secretario general de la FOCh, Enrique Díaz Vera, envió una misiva como parte de cuatro cartas publicadas en El Mercurio- a la comisión parlamentaria y al gobierno solicitando la conformación de la Cámara del Trabajo en la zona carbonífera y la solución de los problemas sociales y económicos que aquejaban a las familias obreras ${ }^{72}$. En abril de 1921 se envió una sub-comisión para estudiar las condiciones de vida de los obreros del carbón, como paso previo para la constitución del Tribunal de Conciliación y Arbitraje transitorio en la zona ${ }^{73}$. La Cámara del Trabajo no se constituyó.

Al verse frustrados los intentos por constituir Cámaras del Trabajo en las distintas regiones del país, y ante el rechazo que recibió el proyecto de Recabarren en el Congreso Nacional, surgieron algunas voces disidentes que se opusieron a la constitución de dichas corporaciones obrero-patronales.

El 1ํ de mayo de 1921, un tal "Andruno del Soviet" publicó un artículo en el que denunció a la Cámara del Trabajo como una institución inútil para resolver los conflictos laborales en favor de los obreros. La nota apareció dos meses después del artículo de Sandalio

\footnotetext{
67 Ibíd, pp. 145-146.

68 "El arbitraje en la zona del carbón”, El Mercurio, Santiago, 16 de febrero de 1921.

69 La comisión parlamentaria especial para la zona carbonífera fue constituida por los senadores Armando Quezada (PR) y Juan Enrique Concha (Partido Conservador) y los diputados; Romualdo Silva Cortés (Partido Conservador), Tomás Ramírez Frías (Liberal "aliancista"), Samuel Claro Lastarria (Liberal "aliancista"), Robinson Paredes (PD) y Belfor Fernández (Liberal Democrático).

70 "La Junta de Conciliación para la zona del carbón", El Mercurio, Santiago, 17 de febrero de 1921.

71 “La Junta de Conciliación para la zona del carbón”, El Mercurio, Santiago, 19 de febrero de 1921.

72 "Las dificultades en la zona carbonífera", El Mercurio, Santiago, 19 de febrero de 1921.

73 "Informaciones Generales. Los obreros del carbón”, El Mercurio, Santiago, 9 de abril de 1921, p. 13; "Legislación Minera”, El Mercurio, Santiago, 16 de abril de 1921, p. 14.
} 
Montenegro en favor de levantar Cámaras del Trabajo en el Norte Grande. El articulista disidente afirmó que:

La Cámara del Trabajo considerada como una panacea, por algunos camaradas, no es tal, es solo una valla para detener el avance del proletariado.

¿Para que (sic) quieren los trabajadores Cámara del Trabajo cuando, si ellos proponen en la Cámara citada, que se les aumente el sueldo, por ejemplo, en un 40 por ciento, se discutirá en la Cámara hasta el cansancio, los representantes obreros harán ver la justicia que les asiste, los patrones, después de alegar mucho, reconocen que los obreros tienen razón, pero dirán que lo que piden los obreros es mucho, nosotros solo podemos darles un 10 por ciento?

Entonces al no estar de acuerdo se nombrará un árbitro, —que jamás será un trabajador y siempre es árbitro una autoridad o un alto empleado fiscal,- que partirá la diferencia y los dejará en un 25 por ciento. A veces encontrará, según él, que los trabajadores no tendrán derecho a pedir tanto; pero sí a aceptar el 10 por ciento propuesto por los patrones.

Por esto se vé, que la Cámara de Trabajo será más salvavidas para los capitalistas, un colchón para amortiguar los golpes; y para los trabajadores, será un lazo que no solamente los ahorcará, sino que también les amarrará las manos, con las que pueden violar los acuerdos yendo a la huelga, y además de esto, queda el descrédito para los que están al frente de la mencionada Cámara.

En Magallanes, por ejemplo, existiendo Cámara del Trabajo, se incendió el local de la Federación, se fondearon obreros, se violaron domicilios, hubo allá, tal vez, más terror que aquí [Antofagasta] ¿Entonces para qué sirve la Cámara de Trabajo si no se da garantías a los trabajadores, pudiendo los capitalistas violar los acuerdos porque tienen las fuerzas militares a su disposición?

Lo único bueno es la organización, esa es el arma que tenemos los obreros que engrandecer cada día más y más y que, en época no muy lejana, les traerá su emancipación. La Tercera Internacional que es el sol que alumbra al proletariado, no aconseja formar Cámaras del Trabajo, porque eso es traicionar al Pueblo que desea emanciparse por sí mismo ${ }^{74}$.

La mordaz crítica realizada por Andruno del Soviet integró un elemento novedoso. El cierre de su exposición literaria utilizó como apoyo un argumento de autoridad: la formación de la Internacional Comunista (IC) o Tercera Internacional no aconseja formar Cámaras del Trabajo. Durante el año 1921 la FOCh y el POS realizaron los preparativos para los congresos que en enero de 1922 transformaron a la primera en parte de la Internacional Sindical Roja (ISR) y al segundo en Partido Comunista, sección chilena de la IC. Sin profundizar en el proceso de adopción de los postulados bolcheviques, en sus inicios, dicha conversión fue más formal que real. Como sostuvo Sergio Grez, el PC mantuvo la misma estrategia política del POS hasta la muerte de Recabarren y posterior a ella, hasta que se produjo la "bolchevización" en la década de $1930^{75}$. No obstante, es posible observar la adopción de tácticas defensivas propias de la IC como fueron las "guardias rojas" durante la huelga carbonífera de enero hasta marzo de $1922{ }^{76}$.

Por lo tanto, el artículo de Andruno del Soviet evidenció por la negativa la estrategia política seguida por la FOCh hasta ese momento histórico. Más allá de si la crítica fue correcta o no, lo cierto es que patentó la existencia de una discrepancia al interior de la FOCh por las estrategias sindicales en curso y de cómo transitar al socialismo desde las organizaciones gremiales.

¿No habrá sido una señal del futuro choque al interior de la FOCh entre las tendencias socialistas corporativistas y las socialistas marxistas? Si las Cámaras del Trabajo constituyeron

74 “La Cámara del Trabajo", El Socialista, Antofagasta, 1ํ de mayo de 1921.

75 Grez, op. cit, 2011, pp. 173-345.

76 Ibíd., pp. 181-193. 
una valla para el avance del pueblo trabajador, ¿por qué el Estado, las patronales y los partidos oligárquicos se opusieron a su aplicación en las industrias chilenas?

\section{El proyecto de Cámara del Trabajo de la FOCh y el proyecto de Código del Trabajo del Partido Conservador: ¿adaptación de "principios"?}

Según Juan Carlos Yáñez, el proyecto de Cámara del Trabajo de la FOCh, "se adaptaba a los principios reconocidos por el proyecto conservador presentado al Senado en 1919 y los convenios de la OIT."77 Es cierto que el proyecto reconoció una serie de demandas - jornada laboral de ocho horas diarias, prohibición de trabajar a menores de 14 años y tribunales de conciliación- que también estuvieron contemplados en la OIT y el proyecto conservador. En este último la presencia de elementos corporativistas resulta evidente. Sin embargo, el escenario político y económico internacional de la posguerra había convertido dichas demandas en "derechos universales" reconocidos por los principales Estados capitalistas del mundo. Por ello resulta necesario someter a crítica dicha afirmación y establecer algunas sutiles diferencias entre ambos proyectos, las que descansaron en fundamentos estratégicos diferentes.

La FOCh propuso un organismo que nucleara al capital y el trabajo con el objetivo de resolver el conflicto en beneficio de ambas partes. En cambio, la propuesta de Concha otorgó todas las facilidades a los empresarios: de existir un arbitraje que los patrones considerasen perjudicial para la empresa, a diferencia de los obreros, aquellos podían ignorarlo ${ }^{78}$. Por esta razón, años más tarde, esta disposición legal produjo una fuerte oposición en los trabajadores, ya que tuvo por objetivo limitar el derecho de huelga. El resultado fue la Ley de Tribunal de Conciliación y Arbitraje despachada en 1924 — que por todas sus falencias, ambigüedades, y vacíos legales - no tuvo aplicación real alguna hasta 193279.

Por otro lado, la Cámara del Trabajo tuvo por objetivo regular todos los aspectos sociales, económicos y culturales de la vida de los trabajadores para asegurar su bienestar 80 . Esto no estaba contemplado en el proyecto conservador. Se debe comprender que para la FOCh, la Cámara del Trabajo era un paso en la vía al socialismo, entendido como conquistas sociales graduales en beneficio de los trabajadores. En cambio, el proyecto de Juan Enrique Concha tuvo por fin frenar y controlar cualquier acción independiente de la clase trabajadora ${ }^{81}$.

El proyecto de Cámara del Trabajo persiguió el objetivo de entregar mayores márgenes de poder social a los trabajadores, otorgándole el derecho de ejecutar decisiones. La constitución de las cámaras tuvo como premisa la organización territorial entre empresas de similar rubro productivo. Por el contrario, el proyecto conservador buscó restarle poder de decisión a los sindicatos (que además tenían que ser creados por los patrones), limitando su margen de acción al lugar de la empresa, sin especificar nada acerca de la conformación de centrales sindicales ${ }^{82}$.

\footnotetext{
77 Yáñez, op. cit, 2008, p.160.

78 Morris, op. cit, p.110.

79 Rojas, op. cit, 1993, p. 62.

80 “Un proyecto importante de la Federación Obrera de Chile. Cámara del Trabajo", El Despertar de Los Trabajadores, Iquique, 7 de enero de 1921.

81 Al respecto ver: Morris, op. cit, 109-127.

82 Ibid, p. 109.
} 
Si bien ambos proyectos de Cámara del Trabajo y Tribunal de Conciliación fueron rechazados por la Comisión de Legislación Social de la Cámara de Diputados, hasta por lo menos inicios de 1922, en la zona carbonífera, la FOCh mantuvo su postura de instalar una Cámara del Trabajo local 83 .

\section{El proyecto de Recabarren: "por la colaboración de todos los habitantes de la nación"}

El proyecto de Cámara del Trabajo o Tribunal de Conciliación elaborado por el diputado Recabarren, se propuso crear organismos colegiados y paritarios de empresarios y trabajadores en cada provincia del país, que legislaran acerca de todos los ámbitos de la organización del trabajo al interior de las empresas y ejecutaran a su vez lo acordado. El espíritu que animó la elaboración del proyecto fue de colaboración de todos los habitantes de la nación para resolver los problemas sociales y construir el bienestar y el porvenir que necesita la mayoría del país ${ }^{84}$. El proyecto se apoyó en la promesa realizada por el nuevo gobierno de "afrontar francamente los problemas sociales" 85 . Recabarren se propuso crear cuerpos legislativos en cada provincia del país que resolvieran los problemas que se suscitaran entre el capital y el trabajo. Sorprende la disposición de esperanza del dirigente obrero en delegar en el Parlamento la decisión de "entregar a obreros y patrones de cada provincia el derecho a legislar sobre sus respectivos intereses (...)" 86 .

Apoyándose en la supervisión y aprobación del Estado, el artículo $2^{\circ}$ estableció que el Tribunal de Conciliación funcionaría "conforme al reglamento que el mismo determine con aprobación de la Oficina del Trabajo o Ministerio del Trabajo (...)" ${ }^{87}$. Al ser promulgada la ley, los intendentes tendrían la responsabilidad de crear las Cámaras y de comunicarlo al gobierno (Art. 33), y colocar a disposición de la Cámara “(...) la fuerza pública, cuando sea requerida la publicación y sanción de esta ley” (art 30). De este modo, el “Tribunal tendrá a su cargo, resolver todo lo que se relacione con la vida industrial y comercial de la provincia" (Art. 4) ${ }^{88}$. Por último, el proyecto estableció que "los gastos que origine la Cámara del Trabajo serán costeados por iguales partes, entre el Estado, la Federación Obrera y la organización patronal” (Art. 28) ${ }^{89}$.

El proyecto del diputado socialista y federado alentó la injerencia del Estado en la resolución del conflicto laboral, erigiéndolo como árbitro y mediador entre las partes. A diferencia del proyecto de la FOCh de 1920, la Cámara estaría compuesta por cinco delegados de la FOCh y cinco delegados patronales. No existió un onceavo participante que actuara como árbitro en las negociaciones entre las partes. Esto llevó al prócer obrero a establecer que en caso de tres empates repetidos en distintas sesiones, el litigio entre el capital y el trabajo "será resuelto por una comisión de tres personas que nombrará el Presidente de la República, ante el

\footnotetext{
83 “Coronel. De la Región Minera (sector de Schwager)”, La Federación Obrera, Santiago, 4 de enero de 1922.

84 "Cámara del Trabajo o Tribunales de Conciliación", El Socialista, Antofagasta, 25 de julio de 1921. Texto completo, aunque con palabras ilegibles, en “Cámara del Trabajo o Tribunales de Conciliación”, La Federación Obrera, Santiago, 21 de agosto de 1921.

85 Ídem.

86 Ídem.

87 "Cámara del Trabajo o Tribunales de Conciliación", El Socialista, Antofagasta, 26 de julio de 1921. Se debe recordar que en ese mismo año la FOCh propuso al gobierno de Alessandri la creación de un Ministerio del Trabajo con participación de autoridades estatales y representantes obreros. Al respecto ver: Mellado, op. cit, 2017, pp. 73-74. 88 "Cámara del Trabajo o Tribunales de Conciliación", El Socialista, Antofagasta, 26 de julio de 1921.

89 “Cámara del Trabajo o Tribunales de Conciliación”, El Socialista, Antofagasta, 28 de julio de 1921.
} 
cual pueden alegar las partes interesadas"90. También se otorgó la facultad a los Intendentes de las provincias de presidir las Cámaras del Trabajo (Art. 26).

Respecto al objetivo y atribuciones de la Cámara, el proyecto de ley de Tribunal de Conciliación se propuso "(...) entregar a obreros y patrones de cada provincia el derecho a legislar sobre sus respectivos intereses para solucionar bajo un espíritu estricto de justicia las dificultades que crea el derecho social del presente". En el Artículo 6, las atribuciones que se le entregaron a la Cámara del Trabajo fueron las siguientes:

1‥ Reglamentar las condiciones del trabajo o prestaciones de servicio en cada caso que sea necesario.

2․․ Fijar salarios o precios mínimos por la realización de trabajos al día, a la semana, al mes o por pieza.

3ํ․ Fijar horarios ordinarios que en ningún caso excederán de 48 horas por cada semana de siete días en trabajos diurnos y de 42 horas de trabajos nocturnos;

4o. Establecer las condiciones de horario extraordinarios o turnos según las industrias;

5o. Reglamentar las condiciones higiénicas de los sitios del trabajo y de las habitaciones que ocupan los personales, cuando estas habitaciones sean propiedad de los industriales, construidas cerca de los sitios del trabajo, como ser en las minas salitreras, fundos o haciendas, vías férreas, etc.

6o. Intervenir y controlar la administración de las respectivas empresas, contratistas o cooperativas obreras de trabajo;

7으. Reglamentar servicios sanitarios y aplicar la ley de accidentes.

8‥ Fijar los precios de los productos.

9o. Fijar anualmente el porcentaje de la utilidad que debe repartirse entre el personal o devolverse a los consumidores.

10. Reglamentar o suprimir el trabajo que se hace por contratistas que se valgan de más de dos obreros para su realización;

11. Organizar un sistema de trabajo por medio de cooperativas obreras;

12. Reducir el número de establecimientos de una misma industria con fines de economía social, acordando la forma de indemnización al artículo 16.

También se contemplaron multas tanto a los patrones como a los consejos federales que no cumplieran los acuerdos tomados por la Cámara del Trabajo. En caso de que "los industriales y comerciantes que reincidieran por tercera vez, serán confiscados en sus industrias o comercios que administrarán los obreros o empleados, bajo la vigilancia del Estado y dependencia de la Cámara del Trabajo"91. Las confiscaciones incluían indemnizaciones a los propietarios. También se estableció una reglamentación del derecho de huelga (artículos 19, $20,21,22$ y 39 ).

Llegado a este punto se pueden ordenar algunos enunciados más arriba planteados: primero, el proyecto aseguró una participación paritaria de los trabajadores junto a los patrones en la reglamentación de la organización del trabajo al interior de una empresa; segundo, el proyecto de Recabarren incluyó la intervención del Estado erigiéndolo como árbitro ante cada conflicto laboral no resuelto por el Tribunal o Cámara del Trabajo. A su vez, al igual que el proyecto de la Cámara del Trabajo votado por la FOCh en 1920, el proyecto del diputado socialista privilegió a la central sindical el derecho de participación en los tribunales de conciliación, aunque otorgó el derecho a las organizaciones no pertenecientes a la FOCh de enviar un delegado "entre los cinco que establece el artículo $1^{\underline{0}}$, inciso a)". ¿A caso esta no

90 “Cámara del Trabajo o Tribunales de Conciliación”, El Socialista, Antofagasta, 27 de julio de 1921.

91 Ídem. 
constituía una vía para cumplir el objetivo trazado en la declaración de principios de la Convención de 191992 que afirmó que la FOCh sustituiría al sistema capitalista en la administración de la producción y distribución de bienes y servicios?

El proyecto de ley se mantuvo en concordancia con el proyecto de Constitución Socialista Federal para Chile y con los principios defendidos en la Convención de la FOCh de diciembre de 1919. Era la "vía fochista" al socialismo: constituir un nuevo Estado popular que combinara organismos de representación y/o autoorganización de los trabajadores con instituciones del Estado capitalista parlamentario.

\section{El Contrato de Socialización Industrial}

El Contrato de Socialización Industrial constituye el más interesante de los tres proyectos levantados por la $\mathrm{FOCh}^{93}$. Primero, propuso la administración común de las industrias y el comercio nacional mediante un acuerdo entre el capital y el trabajo, en función de avanzar en la co-propiedad privada de las mismas. Segundo, fue defendido por dirigentes de la FOCh de orientación socialista más cercana al corporativismo o sindicalismo "puro", en contraste con el socialismo más inclinado hacia el marxismo de Recabarren.

La finalidad del proyecto fue reemplazar "la relación jurídica de arrendamiento de servicios [en la industria], por un contrato de compañía cuyos factores serán el capital y el trabajo"94. Lo que distingue al Contrato de Socialización Industrial de las Cámaras del Trabajo es que el primero tuvo como eje central la participación paritaria de los obreros en la administración y gestión de la producción y en la distribución igualitaria de las ganancias con la parte patronal. En su artículo 1을 definió el Contrato de Socialización Industrial como "un contrato de compañía por el cual el patrón y el obrero estipulan poner respectivamente un común capital y trabajo para desarrollar actividades en industrias fundamentales y repartirse de los beneficios líquidos"95.

La aplicación del proyecto implicaría la creación de un nuevo orden social al interior de cada establecimiento industrial. Este se aseguraría mediante el reemplazo del "contrato por arriendo de servicios" entre patrones y obreros - vigente hasta el momento en ausencia de un Código del Trabajo-, por el "contrato de sociedad" que permitiría la administración común de la industria ${ }^{96}$. El procedimiento se realizaría según lo establecido en el Código Civil que regulaba ambas disposiciones mencionadas ${ }^{97}$.

\footnotetext{
92 En diciembre de 1919, en Concepción, el III Congreso de la FOCh declaró como principios: “(...) conquistar la libertad efectiva económica y moral, política y social de la clase trabajadora (obreros y empleados de ambos sexos), aboliendo el régimen capitalista con su inaceptable sistema de organización industrial y comercial, que reduce a la esclavitud a la mayoría de la población. Abolido el sistema capitalista será reemplazado por la Federación Obrera, que se hará cargo de la administración de la producción y sus consecuencias". En: "Federación Obrera. La sesión de ayer tarde. Informe de comisiones. Importantes debates. Triunfa la ensena roja. ¡Adelante! Es declarado órgano oficial de la Convención", Adelante, Talcahuano, 27 de diciembre de 1919.

93 Una primera indagación al respecto en: Yáñez, op. cit, 2001.

94 "Santiago. Buscando la socialización de las industrias", EL Socialista, Antofagasta, 24 de febrero de 1921.

95 "Proyecto de Contrato de Socialización Industrial. Aprobado por la Junta Ejecutiva Federal", El Despertar de Los Trabajadores, Iquique, 1ㅇ de marzo de 1921. Reproducido también en el diario El Mercurio de Santiago, bajo el título "Sociabilidad obrera. Sobre legislación social. La FOCh aprueba proyecto de contrato de socialización industrial", 25 de febrero de 1921.

96 "Proyecto de contrato de socialización industrial”, La Federación Obrera, Santiago, 1o de octubre de 1921.

97 El contrato de arriendo de servicios se encuentra en el Título XXVI, "Del contrato de arrendamiento", del Código Civil (1855); y el contrato de sociedad en el Título XXVIII, "De la Sociedad". En ausencia de un sistema moderno de relaciones laborales, estas últimas intentaban regularse según el Código Civil, que no reconocía la relación laboral
} 
Al respecto, el principal impulsor del proyecto, Enrique Díaz Vera afirmó que la comunidad o asociación de aportes entre el capital y el trabajo reemplazarían el "contrato de arrendamientos de servicios el cual fue establecido errada e intencionalmente para privilegiar al régimen capitalista, cercenando el derecho de dominio del aporte del trabajo"98. De este modo, donde hubiese a lo menos diez obreros y empleados se constituiría un Consejo de Administración compuesto de delegados patronales y obreros. Sin embargo, el proyecto contuvo disposiciones que contradijeron sus pretensiones iniciales.

El artículo 7으o otorgó una mayor responsabilidad a la parte patronal en el derecho de propiedad de la empresa, al establecer que la representación legal de la sociedad y la celebración de contratos con el público — si bien serían aceptados previamente por el Consejo de Administración - correspondería al patrón. Por esto no sorprende que en el proyecto no exista alusión alguna a la abolición de la propiedad privada de la empresa. Por el contrario, el Contrato de Socialización Industrial tuvo por objetivo lograr que los trabajadores fuesen copropietarios de la empresa junto a los patrones. En concordancia con esto, Díaz Vera afirmó que uno de los alcances fundamentales de este proyecto era "establecer el régimen de administración común de la industria"99.

Otro aspecto curioso del proyecto fue dejar establecido - al igual que el proyecto de Tribunal de Conciliación de Recabarren - la intervención del Poder Ejecutivo del Estado en las resoluciones de los tribunales de arbitraje. En su artículo $10^{\circ}$, el Contrato de Socialización señaló el establecimiento de tribunales arbitrales en cinco ciudades del país (Antofagasta, Santiago, Concepción, Valdivia y Punta Arenas) distribuidas en las principales zonas geográficas del país. Cada tribunal se compondría "de cinco miembros propietarios y cinco suplentes nombrados por el Presidente de la República, de los cuales cuatro serán industriales, cuatro obreros, designados por la Junta Provincial de la Federación Obrera de Chile del asiento del Tribunal y el quinto será designado por los otros cuatro, y en desacuerdo de estos, por el Presidente de la República" 100.

Sin embargo, existe una sutil diferencia entre el Contrato de Socialización Industrial y el proyecto de Cámaras del Trabajo de Recabarren y el aprobado por la FOCh en 1920. Estos dos últimos enfatizaron en la importancia de la negociación de las condiciones comunes de trabajo con la parte patronal. En cambio, el "Contrato" hizo hincapié en la participación obrera de la administración y reparto igualitario de las utilidades de la empresa. Al respecto, el diario El Mercurio señaló que al "establecer una verdadera cooperación, lo mejor sería hacer desaparecer el proyecto de asociaciones cooperativas que está pendiente de la consideración del Congreso ${ }^{101}$. El proyecto al que hizo referencia la prensa oligárquica fue la futura Ley 4.058 de Cooperativas posteriormente aprobada el 8 de septiembre de 1924. De hecho, con los golpes militares de 1924 y 1925, la promulgación de las leyes sociales institucionalizó el reconocimiento de la negociación colectiva en el ámbito de la empresa eliminando cualquier indicio de participación obrera en la dirección de las actividades productivas, la reglamentación interna de la empresa y el reparto igualitario de las utilidades.

En conclusión, el denominador común que tuvieron las Cámaras del Trabajo o Tribunales de Conciliación, y el Contrato de Socialización Industrial, es la contemplación de

específica entre obreros y patrones, siendo este último el poseedor del capital. Fue recién a partir de septiembre de 1924 con la promulgación de las leyes laborales que se estableció — aunque fuese formal— el contrato de trabajo que reconoció los derechos y deberes recíprocos entre patrones y obreros, congruente con una sociedad moderna. 98 "Proyecto de contrato de socialización industrial", La Federación Obrera, Santiago, 1o de octubre de 1921.

99 Ídem.

100 “Sociabilidad Obrera. Sobre legislación social”, El Mercurio, Santiago, 1o de octubre de 1921, p. 15.

101 “Socialización Industrial”, El Mercurio, Santiago, 26 de febrero de 1921. 
organismos colegiados y paritarios de patrones y obreros que resolvieran los problemas que se suscitasen entre el capital y el trabajo —el Consejo de Administración en el caso del último-, tanto al interior de una empresa como en una rama económica. Su concreción permitiría avanzar en la liberación económica, política, moral y social de obreros y empleados. En concordancia con el programa de la FOCh de 1919, eran el camino para abolir el régimen capitalista.

\section{El Contrato de Socialización Industrial y el ala sindical corporativista-socialista de la FOCh}

En febrero de 1921 la FOCh presentó al Presidente de la República y el Congreso Nacional el Contrato de Socialización Industrial. Por medio de este proyecto la central sindical se propuso "establecer la perfecta armonía entre el patrono y el obrero, de hacer desaparecer las huelgas, de normalizar y fomentar la producción y de asegurar el bienestar económico y social de toda la República". La FOCh afirmó que terminaría con la "relación jurídica de arrendamiento de servicios" regulada por el Código Civil (1855), y establecería el "contrato de compañía, cuyos aportes son el capital y el trabajo, ambos de igual valoración, porque son dos factores igualmente necesarios para producir" 102 .

El máximo defensor y propagandista del proyecto fue el Secretario General de la FOCh y Director del periódico carbonífero "La Región Minera", Enrique Díaz Vera103. Meses más tarde se opuso a la transformación del POS en PC en el Congreso del $1^{\text {o }}$ de enero de 1922, proponiendo en su lugar la construcción de un Partido Laborista que resultara de la fusión de la FOCh, el PD y el POS104. Finalmente fue expulsado de la organización sindical. En 1922 fue sustituido por Carlos Alberto Martínez — también opositor a la conversión del POS en PCquien asumió la Secretaria General hasta 1923. Ese año Martínez se marginó de la FOCh105.

Díaz Vera fue el principal difusor de las ideas políticas del "socialismo de principios evolucionistas" al interior de la FOCh, evidenciando una fuerte impronta corporativista en su propuesta. En la prensa federada declaró que

(...) este proyecto acusa un valioso y experimentado concurso a las leyes que el nuevo Gobierno [de la Alianza Liberal y su Presidente Arturo Alessandri Palma] debe dictar, para producir la armonía indispensable en los grandes factores Capital y Trabajo, es también el más rotundo desmentido para todos aquellos espíritus apocados y pusilánimes, que han creído ver en todos los francos actos de la Federación Obrera de Chile, el bolcheviquismo encubierto, y a los agitadores profesionales que viven a expensas de las huelgas.

La Federación Obrera de Chile, con sus estatutos reformados en las memorables Convenciones de Valparaíso en el año 1917 y en Concepción en 1919 va de la mano con el progreso y con los principios evolucionistas. 106

\footnotetext{
102 “La Federación Obrera de Chile y Las Leyes de Legislación Social”, El Despertar de los Trabajadores, Iquique, 5 de marzo de 1921.

103 “Concepción. Para la Jornada Comunista, del bachiller en Leyes y Ciencias Políticas, compañero zapatero A. Quevedo", La Federación Obrera, Santiago, 29 de diciembre de 1922.

104 Acerca de esta discusión ver, Grez, op. cit, 2011, pp. 153-170.

105 Ibid, pp. 176-177.

106 “La Federación Obrera de Chile y Las Leyes de Legislación Social”, El Despertar de los Trabajadores, Iquique, 5 de marzo de 1921. Nótese que en el Manifiesto elaborado por la Comisión de Peticiones del III Congreso de la FOCh de 1919 se declaró anteponer "(...) la evolución ante los pavorosos efectos de la revolución y así, habremos probado al mundo el valor de nuestra acción”. En, Barría, op. cit, p. 126.
} 
Como se indagó en otro artículo107, en septiembre de 1921 Díaz Vera envió una carta al Presidente de la Comisión de Legislación Social de la Cámara de Diputados, el diputado federado Luis Correa Ramírez, solicitando la aprobación del proyecto de la FOCh. En ella reafirmó que los estatutos de la FOCh de 1917 y 1919 "iban de la mano con el progreso y con los principios evolucionistas" y manifestó su apoyo a "S. E. el Presidente de la República en orden de ayudar al pronto estudio del Código del Trabajo, elevado por el Gobierno a la deliberación del Congreso en mayo del año en curso"108. Por último, recomendó "el estudio de este proyecto y su inclusión en el Código del Trabajo"109.

El proyecto fue aprobado por la JEF de la FOCh. Formaron parte de esta en Santiago: Luis Emilio Recabarren, Manuel Hidalgo, Antonio Rodríguez, Eduardo Bunster, Carlos Alberto Martínez y Díaz Vera. Nótese que, a la expulsión de este último de la FOCh en 1922, se agregaron las delimitaciones de Rodríguez y Bunster. Estos fueron expulsados de la central sindical por las mismas razones que los anteriores y por oponerse a la identificación del diario La Federación Obrera como organismo de prensa del PC ${ }^{110}$. Lo sorprendente es que en 1921, de los seis máximos dirigentes de la JEF en Santiago, cuatro correspondieron a una verdadera ala sindical evolucionista o corporativista, más cercana al "sindicalismo puro"111 (Bunster) que al sindicalismo que confluyó con el comunismo (Recabarren e Hidalgo).

Se pude afirmar que la orientación socialista evolutiva de la FOCh del periodo 1919 a 1922 posibilitó la coexistencia de dos tendencias políticas que al final cristalizaron en dos corrientes políticas opuestas: un sector que transitó al socialismo marxista (organizado en el PC) ${ }^{112}$ y otro a una especie de socialismo o sindicalismo corporativo - que como se verá en el párrafo siguiente, posteriormente se comprometió en diversos grados con el programa de legislación social de Carlos Ibáñez del Campo.

Años más tarde, en noviembre de 1925, Martínez y Rodríguez formaron-junto a un centenar de dirigentes sindicales, entre ellos el conspicuo dirigente tranviario de la FOCh y futuro diputado Luis Ayala113 - la Unión Social Republicana de Asalariados de Chile (USRACh), como culminación del proceso de formación de una tendencia socialista corporativa ${ }^{114}$. En 1927 la USRACh apoyó la candidatura presidencial del Coronel Ibáñez ${ }^{115}$.

Sin embargo, a pesar de que el Contrato de Socialización Industrial hizo un llamado explícito a las elites de contribuir a la paz social y a la armonía entre el capital y el trabajo, la lectura que realizaron los parlamentarios oligárquicos del proyecto fue diametralmente opuesta.

\footnotetext{
107 Mellado, op. cit, 2017.

108 “Carta Abierta. Junta Ejecutiva Federal. Al diputado Luis Correa Ramírez”, La Federación Obrera, Santiago, $1^{\circ}$ de octubre de 1921; “Sociabilidad Obrera. Sobre Legislación Social”, El Mercurio, Santiago, 1o de octubre de 1921, p. 15. 109 "Proyecto de contrato de socialización industrial”, La Federación Obrera, Santiago, 1o de octubre de 1921.

110 “A propósito de una encuesta”, La Federación Obrera, Santiago, 30 de julio de 1923; "Antonio Rodríguez retratado por sí mismo", La Federación Obrera, Santiago, 29 de mayo de 1924.

111 Jorge Rojas definió el sindicalismo puro como "un tipo de doctrina o pensamiento dentro de los sindicatos basado en la acción permanente en torno al gremio y sus propias aspiraciones, agrupando sólo a trabajadores (y no a patrones) para conseguir su bienestar económico inmediato, fundamentalmente, sin una finalidad de transformación revolucionaria de la estructura social”. En Rojas, op. cit, 1993, p. 98.

112 En el joven PC chileno, también hubo una fuerte permeabilidad de las tendencias corporativistas que saldrán a la luz en todo su esplendor cuando Ibáñez asuma el poder del Estado. De los 8 parlamentarios comunistas, la mitad apoyó el proyecto ibañista: José Santos Córdova (Antofagasta), Pedro Reyes (Antofagasta), Ramón Sepúlveda Leal (Viña del Mar) y Abraham Quevedo (Valdivia). Al respecto ver: Rojas, op. cit, 1993, pp. 110 y 113.

113 José Díaz, Militares y Socialistas en los años veinte. Centro de Estudios Estratégicos, Universidad ARCIS, 2002, pp. 209-210.

114 Rojas, op. cit, 1993, pp.77-85.

115 Ibid, p. 82.
} 


\section{La oposición oligárquica a los proyectos laborales de la FOCh}

En abril de 1921, el Senador Carlos Aldunate Solar (del Partido Conservador) se hizo la siguiente pregunta respecto al proyecto de ley de Contrato de Socialización Industrial: “¿Es necesaria una ley para que se pueda celebrar en Chile un contrato de compañía entre el patrón y los obreros, por el cual se estipule que una de las partes pone el trabajo y la otra el capital, y que las ganancias se han de dividir? No, cualquiera puede celebrar hoy en día este contrato (...) De aquí se deduce que en las industrias fundamentales, el contrato de participación, mitad y mitad, no es voluntario sino forzoso, no sería contrato propiamente hablando, sino una imposición legislativa"116.

El Senador Aldunate consideró el proyecto "como un primer ensayo de tendencias francamente comunistas" y de la creación de "un Estado dentro del Estado" donde "las facultades del Gobierno para la conservación del orden y el respeto de las instituciones va disminuyendo ostensiblemente". El parlamentario advirtió que el proyecto de la FOCh podía generar una situación semejante a la de Rusia. Afirmó que en este país se había comenzado por el "secuestro" de las empresas por grupos de trabajadores que impusieron la "fiscalización obrera". Sus afirmaciones se apoyaron en el libro del economista ruso exiliado Simón Zagorsky, La República Soviética. Su organización. Su obra. Según este autor, los grupos de fiscalización terminaron por expulsar a los dueños de las empresas de los órganos de reglamentación, que quedaron en manos de los obreros. En otras palabras, apoyándose en la obra de Zagorsky, Aldunate afirmó que el Contrato de Socialización podía llevar a la instauración de un régimen soviético en Chile.

Sus exhortaciones se apoyaron en los acontecimientos ocurridos en el territorio carbonífero. Como se vio más atrás, en dicha zona se produjo una gran huelga a inicios de 1920 y otra a fines del mismo año. Como resultado de las sucesivas huelgas y el intento de constituir un Tribunal de Arbitraje, el senador denunció la constitución en Curanilahue "de un tribunal sovietista que durante algunas horas tuvo dominado a todo el pueblo" 117 .

Más allá de que pudiese parecer una exageración, el discurso del parlamentario oligárquico en la Cámara Alta denotó el temor de las clases propietarias chilenas ante la institucionalización legal de cualquier intento de los trabajadores por incidir en la dirección de la administración de las empresas. El Contrato de Socialización llevó implícito una limitación al derecho empresarial de apropiarse de la totalidad de los medios de producción al considerar a los trabajadores como copropietarios de la industria. No obstante, como ya se vio más arriba, el artículo 7ํ del proyecto entregó a la parte patronal la representación legal de la sociedad y la celebración de contratos con otras entidades, aceptados previamente por el Consejo de Administración. Aldunate reiteró su llamado al gobierno de que "el Presidente de la República y el Congreso vean hasta dónde puede llegarse en esta suave pendiente de las concesiones a estos organismos sovietistas (...) que no tardan en convertirse después en una dirección superior o trust, hasta llegar al dominio del Estado".

En agosto de 1921, el diputado Jorge Hörmann (del Partido Nacional) denunció en el Congreso los proyectos de ley de la FOCh. El parlamentario era un empresario industrial miembro de la organización patronal chilena Sociedad de Fomento Fabril (SOFOFA). Hörmann sostuvo "que cuando la Honorable Cámara deba tratar el proyecto de ley que crea Cámaras del

116 “Congreso Nacional. Cámara de Senadores. 92a sesión extraordinaria”, El Mercurio, 19 de abril de 1921, p. 5; “92ª sesión extraordinaria en 19 de abril de 1921”, Boletín de las Sesiones Extraordinarias del Senado, Santiago, 1921, pp. 1824-1826.

117 Ibíd, p. 1825. 
Trabajo o Tribunales de Conciliación, presentado por el muy honorable señor don Luis E. Recabarren (...) ha de rechazar de lleno el tal proyecto, que encierra ideas comunistas que llevarán al país derecho a la ruina"118.

El diputado oligarca se lanzó contra Luis Emilio Recabarren denunciando el proyecto de Cámaras del Trabajo como el intento de instaurar el comunismo. El argumento de fondo era que dicho proyecto entregaba gran poder de decisión a los trabajadores al interior de las empresas. El proyecto contempló: 1) participación en la administración de las industrias, 2) fijación de precios de los bienes producidos, y 3) fijación anual del porcentaje de las utilidades que debían repartirse obreros y patrones. El diputado nacionalista en su invectiva a Recabarren denunció el poder que se quería entregar a los Consejos Federales en la organización de la producción y la fijación de los precios de las mercancías en una empresa. Esto sería una arbitrariedad en contra de los patrones y la muerte de la "iniciativa particular".

Al igual que el proyecto de Socialización Industrial criticado por Aldunate, para Hörmann las Cámaras del Trabajo constituyeron la vía al comunismo en Chile. Resulta evidente que en septiembre de 1921 estallara la crisis al interior de la Comisión Permanente de Legislación Social de la Cámara de Diputados y Luis Correa Ramírez terminara anunciando su renuncia. El mismo destino siguió Recabarren en noviembre de 1921. La oposición a los proyectos de la FOCh fue transversal, incluyendo a parlamentarios demócratas.

Posteriormente, en 1922 se constituyó una nueva Comisión Mixta para discutir los proyectos de ley de la Alianza Liberal. Solo con los golpes militares de septiembre de 1924 y enero de 1925, los proyectos de ley social y laboral aliancistas se promulgaron y adquirieron vigencia en todo el país.

\section{Conclusiones}

En este artículo observamos de qué modo la FOCh no se limitó a apoyar el programa alessandrista y tomó la iniciativa de redactar y elaborar sus propios proyectos de ley del trabajo-Cámara del Trabajo, Tribunal de Conciliación y Contrato de Socialización Industrial. Los tres proyectos laborales fueron el resultado histórico de la experiencia y la práctica social de los trabajadores de ese periodo: la negociación colectiva de facto con los empresarios; el desarrollo de cooperativas obreras de consumo como medio para lograr el bienestar material de la clase trabajadora; y la conquista de posiciones en el Congreso y los Municipios. Si bien la Alianza Liberal y el Partido Conservador presentaron proyectos de legislación social, las coordenadas desde donde se levantaron los proyectos de la central sindical fueron diferentes.

Los proyectos de la FOCh condensaron el reconocimiento de derechos laborales mínimos con un alto grado de participación de los trabajadores en la organización del trabajo y el proceso productivo. Esto debido a que los proyectos de la FOCh fueron concebidos como un punto de apoyo en el avance hacia la extinción del capitalismo y por lo tanto, de la construcción del socialismo, en concordancia con los principios votados en diciembre de 1919. No obstante, se hace necesario plantear algunas observaciones.

En primer lugar, la finalidad de los proyectos laborales fue institucionalizar un alto poder de decisión a los trabajadores en la regulación de las relaciones laborales y el mercado de trabajo local. El medio para cumplir dicho objetivo sería con la creación de organismos de

118 “Congreso Nacional. Cámara de Diputados. Cuestión Social”, El Mercurio, 4 de agosto de 1921, p. 7 y p. 9 ; “45a sesión ordinaria en 3 de agosto de 1921”, Boletín de Sesiones Ordinarias en 1921. Cámara de Diputados, Santiago, pp. 1474-1483. 
colaboración entre trabajadores y empresarios, ya fuesen Cámaras del Trabajo o Tribunales de Conciliación. Estas instancias de colaboración entre el capital y el trabajo podrían interpretarse como la adopción de principios corporativistas por parte de la FOCh. Como se analizó en la primera parte de este artículo, el corporativismo o funcionalismo puede significar la aplicación de diferentes proyectos políticos. Si bien sus fundamentos se orientan hacia la conciliación entre las clases o las "fuerzas vivas de la nación", pueden ser utilizados de modo táctico para el avance de la lucha de clases. El problema reside en que la adopción de la FOCh de postulados corporativistas trajo como resultado una práctica política ambigua. Por un lado, la adopción del corporativismo pudo plantearse de modo consciente como una táctica pragmática y defensiva para crear condiciones más propicias para la construcción del socialismo. Por otro lado, obligó a la FOCh entrar en un terreno político escabroso de diálogo con las patronales y los poderes públicos, inclinándose por un discurso más moderado hacia estas. Esto produjo las condiciones para que adquirieran visibilidad sectores más conservadores de la FOCh en la discusión de los proyectos de ley. El caso de Enrique Díaz Vera es muestra fehaciente de este último proceso.

En segundo lugar, a pesar de que se buscó la creación de órganos obrero-patronales en la resolución de los problemas que afectaban a los lugares de trabajo, los parlamentarios oligárquicos rechazaron de plano las propuestas legislativas. Para la oligarquía la aprobación de los proyectos habría constituido un avance en la instalación de un régimen soviético en Chile. La afirmación no pareciera ser exagerada si se ciñe a las declaraciones de la FOCh de que la aprobación de los proyectos permitiría sentar mejores condiciones de avance hacia el socialismo - más allá de que no siguiera el modelo de la República Soviética. Por lo tanto, cualquier intento de los trabajadores de acrecentar su poder de decisión económica al interior de las empresas sería rechazado por la oligarquía.

Tercero, los proyectos laborales fueron propuestos al Congreso en una coyuntura social y política de debilitamiento de las organizaciones obreras, aunque favorable a la reforma social debido al triunfo presidencial de Alessandri. La situación desfavorable a movilizaciones ofensivas de los trabajadores y una coyuntura de elecciones parlamentarias donde el elemento político pasó a ser el centro de la actividad de los partidos, favoreció la presentación de proyectos de ley con un contenido más defensivo, orientados a resolver los problemas que afectaban el funcionamiento y marcha de las empresas. Esto explicaría por qué los proyectos no plantearon la abolición de la propiedad privada de las empresas. Como se vio con el proyecto de Contrato de Socialización Industrial, este se inclinó hacia la copropiedad de los establecimientos productivos. El único proyecto que se propuso la abolición de la propiedad privada de los medios de producción y su administración por las "asambleas industriales" de trabajadores fue el proyecto de Constitución de República Federal Socialista de Recabarren, el cual no corresponde a los proyectos laborales presentados al Congreso. Por ello, no se puede afirmar - como sostuvo Yáñez - que los proyectos laborales de la FOCh se adecuaron sin mayores diferencias al "espíritu conciliador que suponía la dictación de la legislación social", o a los "principios" del proyecto conservador por el solo hecho de contemplar demandas democráticas que estuvieron integradas en este último. El énfasis en entregar poder de resolución a los trabajadores marcó una diferencia fundamental desde el inicio.

Por último, no se encontró en las fuentes registro alguno de la realización de movilizaciones obreras en favor de los proyectos de ley de la FOCh presentadas al Congreso. Se debe recordar que la situación económica y la fuerte represión patronal del bienio de 19211922 contribuyeron a desactivar al movimiento laboral. Todo indica que en aquel breve periodo la presión de la FOCh por legislación social quedó limitada al debate parlamentario, sin llegar a 
materializarse en un movimiento de trabajadores unificado en las empresas y las calles por dicha demanda.

\section{BIBLIOGRAFIA}

\section{Libros y tesis:}

Barría Serón, Jorge, Los movimientos sociales de Chile. Desde 1910 hasta 1926 (Aspecto político y social), Memoria de Prueba para optar al Grado de Licenciado en Ciencias Jurídicas y Sociales, Universidad de Chile, Editorial Universitaria, 1960.

Barría Serón, Jorge, El movimiento obrero en Chile. Síntesis histórico-social, Santiago, Colección Trígono, 1971.

Duguit, León, La transformación del Derecho Público, Madrid, 1913.

Durán Mateluna, Francisca, La Federación Obrera de Chile, 1909-1921: De la Organización Mutual al Frente Común. Pontifica Universidad Católica de Chile. Facultad de Historia, Geografía y Ciencias Políticas. Instituto de Historia. Profesor Guía: Julio Pinto Vallejos. Santiago, 2002.

Díaz, José, Militares y Socialistas en los años veinte. Centro de Estudios Estratégicos, Universidad ARCIS, 2002.

Gramsci, Antonio, “Análisis de situaciones y relaciones de fuerzas”, Cuaderno $13 \S 17$ (19321934), Cuadernos de la Cárcel, Tomo 5, Ediciones Era, 1975.

Grez Toso, Sergio, Historia del Comunismo en Chile. La era de Recabarren (1912-1924), Santiago, Lom ediciones, 2011.

Grez Toso, Sergio, El Partido Democrático de Chile. Auge y ocaso de una organización política popular (1887-1927), Lom ediciones, 2016.

Hobsbawm, Eric, "Marx, Engels y el socialismo premarxiano". En: Historia del Marxismo. El Marxismo en Tiempos de Marx (I), Editorial Bruguera, 1979.

Illanes, María Angélica, Chile Descentrado. Formación socio-cultural republicana y transición capitalista (1810-1910), Lom Ediciones, 2003, "El fruto prohibido de la guerra civil: el pueblo como poder. Valparaíso 1891-1897”, pp. 463-494.

Jobet, Julio César, Luis Emilio Recabarren. Los orígenes del movimiento obrero y del socialismo chileno. Prensa latinoamericana, 1971 [1955]. 
Kolakowsky, Lezsek, Las principales corrientes del marxismo. I. Los Fundadores. Alianza Editorial, 1976.

Massardo, Jaime, La formación del imaginario político de Luis Emilio Recabarren, Lom ediciones, 2007.

Mellado Carrasco, Vicente, Del Consejo Federal al Sindicato Legal: la Federación Obrera de Chile (FOCh) y el inicio de la transición a un sistema moderno de relaciones laborales (1919-1927), Universidad de Chile, Facultad de Filosofía y Humanidades, Departamento de Ciencias Históricas, Profesor guía: Sergio Grez Toso, 2013.

Millar, René, La elección presidencial de 1920, Editorial Universitaria, 1981, pp. 115-148.

Morales Álvarez, Jorge Rubén, Estudio sobre los contratos colectivos, Tesis para el Bachillerato en Leyes y Ciencias Políticas de la Universidad de Chile, Santiago de Chile, Apostolado de la Prensa, 1926, p. 83.

Morris, James O., Las elites, los intelectuales y el consenso. Estudio de la cuestión social y el sistema de relaciones industriales en Chile, Santiago, Editorial Universitaria, 1967.

Ortiz Letelier, Fernando, Historia del movimiento obrero en Chile. 1891-1919, Lom ediciones, 2005 [1956],

Ramírez Necochea, Hernán, Origen y Formación del Partido Comunista de Chile, Editorial Progreso, 1984.

Pinto Vallejos, Julio, Luis Emilio Recabarren. Una biografía histórica, Lom ediciones, 2013.

Ramírez Necochea, Hernán, Obras Escogidas, Santiago, Lom Ediciones, 2007, vol II, pp.151-467 (3르 ed).

Rojas Flores, Jorge, El sindicalismo y el Estado en Chile (1924-1936), Colección Nuevo Siglo, 1986.

Rojas Flores, Jorge, La dictadura de Ibáñez y los sindicatos (1927-1931), Santiago, DIBAM Centro de Investigaciones Diego Barros Arana, 1993. Versión electrónica: http://www.archivochile.com/Ideas Autores/rojasfj/ rojasfj 0001.pdf.

Salazar Vergara, Gabriel, Del poder constituyente de asalariados e intelectuales. (Chile, siglos XX yXXI), Lom ediciones, 2009.

Valencia Avaria, Luis, Anales de la Republica. Textos constitucionales de Chile y registro de los ciudadanos que han integrado los poderes ejecutivo y legislativo desde 1810, Santiago, Editorial Andrés Bello, 1951.

Valenzuela, Humberto, Historia del movimiento obrero en Chile, Editorial Quimantú, 2008 [1976]. 
Varas, José Miguel, Chacón, Sociedad Impresora Horizonte Ltda, 1968.

Vial, Gonzalo, Historia de Chile (1891-1973). Triunfo y decadencia de la Oligarquía (18921-1920), volumen II, Editorial Santillana del Pacífico, santiago de Chile, 1983.

Vitale, Luis, Ensayo de Historia del Movimiento Obrero Chileno. Los discursos de Clotario Blest y la revolución chilena, Editorial POR, 1961.

Vitale, Luis, Interpretación marxista de la historia de Chile, volumen III (tomos V y VI), Lom Ediciones, 2011, pp. 6-314 [Tomo V, "De la Republica parlamentaria a la república socialista (1891-1932)"].

Yáñez, Juan Carlos, La Intervención Social en Chile. 1907-1932, Ril editores, 2008.

\section{Artículos de revistas y capítulos de libros:}

Bastías Saavedra, Manuel, "Intervención del Estado y derechos sociales. Transformaciones en el pensamiento jurídico chileno en la era de la cuestión social, 1880-1925", Revista Historia Pontifica Universidad Católica de Chile, No 48, vol. i, enero-junio 2015: 11-42.

Gramsci, Antonio, “El Partido Comunista y los sindicatos” (1922), en: Escritos Políticos (19171933), siglo XXI editores, 1977, pp. 141-166.

Gramsci, Antonio, “Análisis de situaciones y relaciones de fuerzas”, Cuaderno $13 \S 17$ (19321934), Cuadernos de la Cárcel, Tomo 5, Ediciones Era, 1975, pp. 32-40.

Grez Toso, Sergio, "El escarpado camino hacia la legislación social: debates, contradicciones y encrucijadas en el movimiento obrero y popular (Chile: 1901-1924)", en Cuadernos de Historia, $\mathrm{N}^{\circ} 21$, diciembre de 2001, pp. 119-182.

Grez Toso, Sergio, “¿Autonomía o escudo protector? El movimiento obrero y popular y los mecanismos de conciliación y arbitraje (Chile, 1890-1924)", en Historia, vol. 35, Santiago, 2002, pp. 91-150.

Sergio Grez Toso, "La Asamblea Constituyente de Asalariados e Intelectuales. Chile, 1925: entre el olvido y la mitificación”, en Revista Izquierdas № 29, 1-48, septiembre de 2016.

Matus González, Mario, "Salarios y sueldos reales de los operarios y empleados metalúrgicos industriales chilenos, 1888-1928", en, Mario Matus G. (ed.), Hombres del Metal. Trabajadores ferroviarios y metalúrgicos chilenos en el Ciclo Salitrero, 1880-1930, Ediciones Facultad de Filosofía y Humanidades de la Universidad de Chile, 2009, pp. 49-76.

Mellado Carrasco, Vicente, “¡Por el derecho de asociación y de huelga! La Federación Obrera de Chile (FOCh) y el camino a la legislación laboral (1921-1924)”, en Cuadernos de Historia, № 42, junio de 2015, 85-125. 
Mellado Carrasco, Vicente, "El Código del Trabajo de la Alianza Liberal y la Federación Obrera de Chile (FOCH), 1920-1922”, en Cuadernos de Historia, № 47, diciembre de 2017, pp. 59-84.

Salazar Vergara, Gabriel, “Luis Emilio Recabarren y el Municipio en Chile (1900-1925)”, Revista de Sociología №9, 1994, pp. 61-82.

Trotsky, León, "La cuestión del control obrero de la producción (Carta a los camaradas), 20 de agosto de 1931", en: La Lucha contra el Fascismo en Alemania, Ediciones IPS, Buenos Aires, 2013, pp. 48-55.

Yáñez, Juan Carlos, “Chile y la Organización Internacional del Trabajo (1919-1925). Hacia una Legislación Social Universal”, Revista de Estudios Histórico-Jurídicos, Valparaíso, no 22, 2000, pp. 317-332.

Yáñez, Juan Carlos, "El proyecto laboral de la FOCh (1921). Los trabajadores frente a la Legislación Social”, Espacio de convergencia: primer y segundo encuentro de estudios humanísticos para investigadores jóvenes, Museo Nacional Benjamín Vicuña Mackenna, Santiago, agosto de 1999 y agosto de 2000, editor, Sergio Grez Tozo, 2001.

Valdivia Ortíz de Zárate, Verónica, "Yo, el León de Tarapacá, Arturo Alessandri Palma, 19151932", en Revista Historia, № 32, Santiago, Universidad Católica de Chile, 1999, 485-551.

Venegas Valdebenito, Hernán, "Crisis económica y conflictos sociales y políticos en la zona carbonífera, 1918-1931", Revista Contribuciones Científicas y Tecnológicas, № 116, Santiago, noviembre de 1997, 124-152.

\section{Prensa periódica:}

Adelante, Talcahuano, 1919-1920.

El Despertar de los Trabajadores, Iquique, 1921.

El Socialista, Antofagasta, 1921.

El Mercurio, Santiago, 1921.

La Federación Obrera, Santiago, 1921-1923.

\section{Archivos:}

Cámara de Diputados. Boletín de Sesiones Ordinarias y Extraordinarias (1921). Cámara del Senado. Boletín de Sesiones Ordinarias y Extraordinarias (1921).

\section{Folletería:}

Recabarren, Luis Emilio, ¿Qué es lo que queremos federados y socialistas? Proyecto de Constitución para la República Federal Socialista de Chile, Antofagasta, Imprenta El Socialista, 1921. 